$\begin{array}{llllllllllllll}\text { A T A C H E I C A S C A N D I N A V I C A } & 20 & (1966) & 597-629\end{array}$

\title{
Infrared Spectra of Thioamides and Selenoamides
}

\author{
KAI ARNE JENSEN and PER HALFDAN NIELSEN
}

\author{
Chemical Laboratory II (General and Organic Chemistry), University of Copenhagen, \\ The H. C. Orsted Institute, Copenhagen, Denmark
}

\begin{abstract}
Through a study of the infrared absorption bands of about 150 thioamides, selenoamides, thioureas, and selenoureas (Tables 1-8) it has been possible to locate various characteristic bands. These are termed the thioamide A, B, ...G bands - each of which behave in a characteristic way when the compounds are deuterated, $S$ - or $S e$ alkylated, or transformed into metal complexes. Although it may be extremely difficult to decide from which molecular vibrations these bands originate, it is often easy to locate corresponding bands in the spectra of various thioamides. The $A$ and $E$ bands are only found in the spectra of primary thioamides, and the $F$ band is not found in the spectra of tertiary thioamides. The remaining bands $-B, C, D$, and $G$ bands - are found in the spectra of both primary, secondary, and tertiary thioamides. The $\mathrm{G}$ band seems often to be due to a fairly pure $\mathrm{C}-\mathrm{S}$ (or $\mathrm{C}-\mathrm{Se}$ ) vibration although extensive coupling with $\mathrm{N}-\mathrm{H}$ or other vibrations may occur. With a few exceptions, it is found below $800 \mathrm{~cm}^{-1}$, i.e. in a range usually cited for the single bond $\mathrm{C}-\mathrm{S}$ stretching vibration. On substitution of sulfur with selenium this band is shifted $30-100 \mathrm{~cm}^{-1}$ towards lower frequencies. Except for the $\mathrm{G}$ band the infrared spectra of corresponding thio- and selenoamides are so similar that it is concluded that there is no thioamide band which can rightly be classified as a " $C=S$ band".

Now compounds prepared during this investigation are diselenomalonamide, several thioureas, selenoureas, methiodides, and metal complexes of thioamides, selenoamides, thioureas, and selenoureas.
\end{abstract}

$\mathbf{T}^{\mathrm{s}}$ he infrared spectra of thioamides and related compounds have given rise to much discussion. ${ }^{1-10}$ Most interest in this field has centered on the possibilities of making exact structural assignments rather than discussing the results from a practical point of view. Although the literature clearly indicates that useful diagnostic information can be obtained from the infrared spectra of thioamides, many new data has now been collected on frequency variations with the change of environment and it is the purpose of this report to present and analyze these findings. The present approach should be considered as an adjunct to the unequivocal interpretation of the bands, which involve theoretical calculations. Nevertheless, for identification purposes, the structural features are sufficiently clear to permit of considerable errors in the assignment

Acta Chem. Scand. 20 (1966) No. 3 
of bands to specific vibrations without invalidating the conclusions concerning the presence of the various thioamide structures.

We have been able to locate various characteristic bands in the spectra of thioamides, each of which behaves in a characteristic way, when the compounds are deuterated, $S$-alkylated, or transformed into metal complexes. Most of these bands undoubtedly arise from interactions between various vibrations so it would be arbitrary to use the concept of "a characteristic bond frequency". We have designated them in a non-committal way as A, B, ... G bands. Several authors have spoken of the "Amide II band", "Amide III band" etc., of thioamides but these terms are misleading because there is reason to believe (see later) that these bands will normally not correspond to the amide bands which have been designated by these terms.

In addition to the above-mentioned methods we have as already communicated in a preliminary note, ${ }^{11}$ also used the replacement of sulfur by selenium as a diagnostic probe. The comparison of several spectra of thioamides, thioureas, and thiosemicarbazides with the spectra of the corresponding selenium analogues showed that the spectra of a sulfur compound and its selenium analogue were in most cases virtually superimposable down to $800-900 \mathrm{~cm}^{-1}$. This observation at once provides an answer to the much disputed question of the identification of the " $\mathrm{C}=\mathrm{S}$ stretching vibration", the answer being that such a vibration is not present in the spectra of thioamides. The CS-vibration in the spectra of thioamides has predominantly single-bond character and so should be located in the $600-800 \mathrm{~cm}^{-1}$ region.

Since the replacement of sulfur with selenium essentially changes only the bands due to CS vibrations, this method therefore almost works like an isotopic substitution. In the following we have briefly designated the substitution of sulfur with selenium "selenation" although this process, of course, cannot be carried out directly.

The substitution of sulfur with oxygen, on the other hand, changes the infrared spectrum so completely that it has not been possible to obtain much useful information from a comparison of the spectra of thioamides with the spectra of amides.

This paper is mainly concerned with infrared spectra of thioamides, thioureas, and their selenium analogues. Some data on the spectra of thiohydrazides and thiosemicarbazides (and their selenium analogues) will be included in the relevant places, but a more detailed discussion of the spectra of these compounds will be published in some forthcoming papers. Derivatives of thiocarbamic and dithiocarbamic acids also show some special features in their infrared spectra and will be treated in a future publication.

\section{THE CHARACTERISTIC BANDS}

The $A$ band. The A band is a strong band, usually in the $1600-1650 \mathrm{~cm}^{-1}$ region, found in the spectra of all thioamides, selenoamides, thioureas, and selenoureas, containing an unsubstituted $\mathrm{NH}_{2}$ group, i.e. the group $-\mathrm{CX}-\mathrm{NH}_{2}$ 
$(\mathrm{X}=\mathrm{S}$ or Se).* Exceptionally, the band may be found at a little lower frequencies (dithiooxamide, $1582 \mathrm{~cm}^{-1} ; N, N$-diphenylthiourea, $1595 \mathrm{~cm}^{-1}$ ) or higher frequencies (3-pyridinecarbothioamide, $1680 \mathrm{~cm}^{-1}$ ).

This band corresponds to the well-known "Amide II band of primary amides" (cf. Bellamy ${ }^{12}$ ) and has been shown (in many instances, by deuteration) to originate from the $\mathrm{NH}_{2}$ deformation vibration. It was pointed out by Suzuki ${ }^{6,7}$ that the $\mathrm{NH}_{2}$ bending motion is necessarily coupled with the $\mathrm{C}-\mathrm{N}$ stretching vibration of the neighbouring $\mathrm{C}-\mathrm{N}$ bond. This is reflected, in our experiments, in the shift of the A band to higher frequencies on $S$ - or $\mathrm{Se}$ alkylation, salt formation, e.g. with hydrogen chloride (which is an $S$-protonation, cf. Janssen, ${ }^{13}$ Kutzelnigg and Mecke ${ }^{28}$ ), or complex formation, by which the $\mathrm{C}-\mathrm{N}$ bond assumes a higher degree of double bond character. One exception found was 3-pyridinecarbothioamide (thionicotinamide) which shows a shift of the $\mathrm{A}$ band on complex formation with $\mathrm{CuCl}$ to $1650 \mathrm{~cm}^{-1}$. The reason for this behaviour is that this thioamide is in equilibrium with its tautomeric thiol structure. Another exception is the complex formation of dithiomalonamide with cobalt(II) chloride. However, complexing of dithioamides may be a complicated reaction, $c f$. Hurd et al..$^{14}$

The position of the A band can be used to distinguish these compounds from hydrazides and thiohydrazides. In these compounds, the $\mathrm{NH}_{2}$ group is not adjacent to a $\mathrm{CO}$ or CS group and the $\mathrm{NH}_{2}$ band will, therefore, be found at lower frequencies. In the spectra of 2-substituted thiosemicarbazides, $\mathrm{H}_{2} \mathrm{~N}-\mathrm{CS}-\mathrm{NR}-\mathrm{NH}_{2}$, two $\mathrm{NH}_{2}$ bands are observed of which the one with the higher frequency must be ascribed to the thioamide $\mathrm{NH}_{2}$ group.

Indirect evidence to support the above assignments is indicated by the absence of the $\mathrm{A}$ band in the spectra of all the compounds studied which have no free $\mathrm{NH}_{2}$ group.

The $B$ band. The $\mathrm{B}$ band is a strong band in the $1400-1600 \mathrm{~cm}^{-1}$ range and appears in the spectra of all thioamides, thioureas, thiohydrazides, thiosemicarbazides, and their selenium analogues investigated in this laboratory.

This is a very characteristic band, usually very strong and somewhat broad, which is useful for distinguishing it from absorption peaks due, for example, to the phenyl group, which are generally sharp in shape. Furthermore, this band is very sensitive to complex formation and $S$-alkylation, and we have on no occasions been in doubt as to its location. It has been asserted that this band is missing in the spectra of primary thioamides, but this is actually not the case; however, it may be found at as low frequencies as $1400 \mathrm{~cm}^{-1}$, e. $g$. in the spectrum of thiobenzamide. Generally it is found between 1500 and 1600 $\mathrm{cm}^{-1}$.

In view of the major shift to higher frequencies observed by $S$-alkylation, a decisive feature of the $\mathrm{B}$ band must be a $\mathrm{C}-\mathrm{N}$ vibration, the shift thus being

\footnotetext{
* In spectroscopic literature, amides with the groups $-\mathrm{CONH}_{2},-\mathrm{CONHR}$, and $-\mathrm{CONR}_{2}$ $(\mathrm{R}=$ alkyl or aryl) are usually distinguished by the terms primary, secondary, and tertiary amides. The same terms are, however, also used for mono-, di-, and triacylamines, and the IUPAC Commission on the Nomenclature of Organic Chemistry, therefore, does not recommend their use. Nevertheless, after some hesitation, we have decided to retain these terms because it is obviously more convenient to talk about primary, secondary, and tertiary thioamides than of " $N$-unsubstituted" " $N$-monoalkyl or $N$-monoaryl" and " $N, N$-dialkyl, $N, N$-alkyl-aryl or $N, N$ diaryl" thioamides.
}

Acta Chem. Scand. 20 (1966) No. 3 
explained by the increased double-bond character of the $\mathrm{C}-\mathrm{N}$ bond following alkylation of the sulfur (or selenium) atom. However, a full explanation of this band must obviously be founded on the concept of mixed vibrations, the extent and type of which seem to be highly dependent on the environment of the $\mathrm{C}-\mathrm{N}$ bond.

In the case of primary aliphatic thio- and selenoamides, extensive coupling seems to occur with $\mathrm{CH}, \mathrm{CH}_{2}$ or $\mathrm{CH}_{3}$ vibrations. ${ }^{6,7}$ The shift of the band in the spectrum of thioacetamide from $1470 \mathrm{~cm}^{-1}$ to $1573 \mathrm{~cm}^{-1}$ on $S$-methylation should probably be explained by an increased coupling of the $\mathrm{CN}$ and $\mathrm{CH}_{3}$ vibrations rather than by an increased double-bond character of the $\mathrm{CN}$ bond. In secondary aliphatic thio- and selenoamides, 8,15 the frequency of the CN vibration is sufficiently near to that of the $\mathrm{NH}$ vibration for a coupling to occur. Accordingly, deuteration influences the $\mathbf{B}$ band of secondary thio- and selenoamides. Similar behaviour has been noted by Elmore ${ }^{3}$ in the infrared spectra of cyclic secondary thioamides. We agree with this author in the assignment of the $B$ band in tertiary thio- (and seleno-) ureas to the $\mathrm{C}-\mathrm{N}$ grouping primarily; however, coupling with neighbouring alkyl groups cannot be excluded.

In the spectra of primary aromatic thioamides, the shift of the $B$ band to slightly higher frequencies on deuteration cannot be explained by assuming coupling with the vibrations from the aromatic nucleus, as these are unaffected by deuteration. We therefore conclude that, in the $\mathrm{B}$ bands of these compounds, some admixture of the $\mathrm{NH}_{2}$ band is present. The small shift, observed when going from thiobenzamide to selenobenzamide, also reveals a minor coupling with the $\mathrm{C}-\mathrm{S}$ vibration. As expected, the $\mathrm{B}$ band in $N$-methylthiobenzamide is due to mixed $\mathbf{C}-\mathbf{N}$ and $\mathbf{N}-\mathrm{H}$ vibrations, as found in the aliphatic series.

We consider the B bands in the spectra of thio- and selenoureas to originate chiefly from the antisymmetric $\mathrm{N}-\mathrm{C}-\mathrm{N}$ stretching motion, though probably with some coupling with the $\mathrm{CS}$ (or CSe) and the $\mathrm{NH}$ and $\mathrm{NH}_{2}$ vibrational modes, as is evident from deuteration and selenation experiments. That a coupling with the NH vibration has occurred in the spectra of secondary thioureas is also supported by the observation that the $B$ bands occur as doublets in the spectra of thioureas of the type RNH-CS-NHR', unless the radicals $R$ and $R^{\prime}$ are very similar in mass and structure (such as phenyl and $p$-tolyl), but not in the spectra of trialkylthioureas.

The $B$ band resembles both the strong band near $1550 \mathrm{~cm}^{-1}$ occurring in the spectra of cyclic compounds containing the - CS-NH - group (which was called the "thioureide band" by Randall et al. ${ }^{16}$ (cf. also Refs. 3, 9, 38), and a strong band in the same region in the spectra of $N, N$-dialkyldithiocarbamates studied by Chatt, Duncanson and Venanzi. ${ }^{17}$ The latter w.orkers assign this band to the $\mathrm{C}-\mathrm{N}$ stretching mode shortened under the influence of the resonance structure $R_{2} \stackrel{\oplus}{N}=C_{S^{\ominus}}^{S^{\ominus}}$. As discussed above, this is considered to be an essentially correct description of the origin of the $B$ band.

Other authors, on the other hand, have compared this band with the "amide II band of secondary amides", which is also a strong band near $1550 \mathrm{~cm}^{-1}$. 
In our opinion, however, this comparison is misleading. Although the "amide II band of secondary amides" has some $\mathrm{C}-\mathrm{N}$ character (cf. Miyazawa et al. ${ }^{18}$ ) a major component of this band is the $\mathrm{N}-\mathrm{H}$ vibration. It, therefore, disappears on deuteration and is missing in the spectra of tertiary amides whereas the $B$ band is influenced only little by deuteration and is strong also in the spectra of tertiary thioamides. Further, the B band also occurs in the spectra of primary thioamides whereas primary amides have only the "amide II band of primary amides" which corresponds to our A band. If at all, the B band is comparable with the "Amide I band" and not with the "Amide II band". Both the $B$ band and the amide I band have their origin in the antisymmetrical vibration of the grouping $\mathrm{N}-\mathrm{C}=\mathrm{X}(\mathrm{X}=\mathrm{O}, \mathrm{S}, \mathrm{Se})$, the main difference being that the stretching of the $\mathrm{N}-\mathrm{C}=\mathrm{O}$ grouping has predominantly $\mathrm{C}=\mathrm{O}$ character whereas the stretching of the thioamide or selenoamide group has predominantly $\mathrm{C}=\mathrm{N}$ character. In accordance herewith, it is the amide $\mathrm{I}$ band and not the amide II band which resembles the $\mathrm{B}$ band by being influenced by $O$ alkylation (formation of imido esters and isoureas), $O$-protonation ${ }^{13}$ and complex formation. ${ }^{19}$

The $C$ band. The $\mathrm{C}$ band is in most cases readily observed as a medium to strong band in the $1200-1400 \mathrm{~cm}^{-1}$ region, although it may be found at slightly higher frequencies (e.g. thiourea, $\left.1415 \mathrm{~cm}^{-1}\right)$. We have found this band in the spectra of all thioureas and thioamides and their selenium analogues, and in the spectra of most thiohydrazides. However, the band is usually less pronounced for thioamides and thiohydrazides.

Like the $\mathrm{B}$ band, the $\mathrm{C}$ band is essentially composite in nature. It has been assigned to $\mathrm{C}-\mathrm{C}$ vibration or to a mixture of $\mathrm{NH}_{2}$ rocking and $\mathrm{N}-\mathrm{C}-\mathrm{N}$ and $\mathrm{C}-\mathrm{S}$ stretching vibration. ${ }^{4}$ Since, however, this band occurs also in the spectra of tertiary thioamides the $\mathrm{NH}_{2}$ rocking mode cannot contribute substantially to this band. Furthermore, very little mixing with a CS vibration can occur since the $\mathrm{C}$ band is found in almost the same place in the infrared spectra of thio- and selenoureas.

The $\mathrm{C}$ band in thioureas and selenoureas is considered to be mainly due to the $\mathrm{N}-\mathrm{C}-\mathrm{N}$ grouping, in agreement with Rao et al. ${ }^{10}$ However, in primary and secondary thioamides and thioureas, mixing occurs to a small degree with NH vibrations, as is apparent from deuteration studies. Nevertheless, this band is much less sensitive to deuteration than the amide III band of secondary amides and therefore they probably are not comparable.

Only a small shift of the $\mathrm{C}$ band of thioureas and tertiary thioamides is observed on $S$-methylation. No shift was observed on $S$-methylation of thiobenzamide, whereas the frequency of the $\mathrm{C}$ band of selenobenzamide was raised slightly on Se-methylation. In contrast, the $\mathrm{C}$ band of primary and secondary aliphatic thioamides is shifted significantly to higher frequencies on $S$-methylation. This difference can probably be attributed to the greater weight of the dipolar structure $\mathrm{H}_{2} \stackrel{+}{\mathrm{N}}=\mathrm{C}-\overline{\mathrm{S}}$ for thioureas and aromatic thioamides than for aliphatic thioamides, as is plausible from their dipole moments. The increase in polarity on $S$-alkylation will, therefore, be relatively greater for the aliphatic thioamides. 
In aliphatic thioamides, coupling with $\mathrm{CH}, \mathrm{CH}_{2}$, and $\mathrm{CH}_{3}$ vibrations further seems to be of importance.6,7

The $D$ band. A band of medium strength can be found in the 1000-1200 $\mathrm{cm}^{-1}$ range in the spectra of most thioamides, thioureas, and their selenium analogues, with the exception of symmetrically aromatic disubstituted thioureas. Collard-Charon and Renson ${ }^{15,20}$ considered this band to be due to the CS group; however, the changes induced on selenation seem to be much too small to justify this assignment. Further, our deuteration studies bave shown it to be due chiefly to NH vibrations in secondary thioamides and most thioureas. Only in a few compounds, e.g. thioacetamide and thiourea, does the CS character seem to be recognizable, as the $\mathrm{D}$ band of such compounds is shifted to lower frequencies on $S$-alkylation, i.e. opposite to the $\mathrm{B}$ and $\mathrm{C}$ bands, reflecting the diminished double-bond character of the CS bond following the $S$-alkylation. However, even in these cases, the shifts are very small compared with those found for the $\mathrm{B}$ and $\mathrm{C}$ bands.

For other compounds a shift, equally small, to higher frequencies is observed on $S$-alkylation, which shows that the $\mathrm{D}$ band also has some $\mathrm{C}-\mathrm{N}$ character. These observations indicate that a major contribution to the $\mathrm{D}$ band might be the symmetrical stretching vibration of the $\mathrm{N}-\mathrm{C}-\mathrm{S}$ grouping. S-Alkylation will affect the $\mathrm{C}-\mathrm{N}$ and the $\mathrm{C}-\mathrm{S}$ bond in an opposite way and the net result may therefore be small. However, as mentioned earlier, extensive coupling with $\mathrm{N}-\mathrm{H}$ vibrations occurs in compounds with a primary or secondary thioamide group.

The $E$ band. A characteristic band, usually in the range $800-900 \mathrm{~cm}^{-1}$, appears in the spectra of most thioureas and selenoureas with a primary amino group (except unsubstituted thiourea and selenourea) and thiosemicarbazides. It is also found in the spectra of some primary thioamides but is absent in others. The main contribution to this band is considered to be an $\mathrm{NH}_{2}$ bending mode (wagging). This vibration may couple strongly with other vibrations which accounts for the absence of this band in the spectra of many primary thioamides. On $S$-methylation or complex formation it is often weakened and may disappear completely, probably because the wagging of the $\mathrm{NH}_{2}$ group is more or less inhibited when the double-bond character of the $\mathrm{C}-\mathrm{N}$ bond is increased.

The $\mathrm{E}$ band may be shifted significantly on selenation (see Table 5). However, the fact that it is very sensitive to deuteration and is not shifted, but only weakened, on $S$ - or $S e$-methylation or complex formation, shows that it has its origin in $\mathrm{NH}_{2}$ vibrations.

All spectra of thiosemicarbazides with an unsubstituted 1- $\mathrm{NH}_{2}$ group further have a strong band near $1000 \mathrm{~cm}^{-1}$ which may also be assigned to an $\mathrm{NH}_{2}$ bending mode. In contrast to the $800 \mathrm{~cm}^{-1}$ band, it is unaffected by $S$ methylation or complex formation but disappears on deuteration. It will be discussed more fully in a forthcoming paper on the infrared spectra of thiosemicarbazides.

The $F$ band. A band near $700 \mathrm{~cm}^{-1}$ seems typical for the spectra of most thioamides and thioureas. It has been assigned to $\mathrm{C}-\mathrm{N}$ stretching or to a mixture of $\mathrm{C}=\mathrm{S}$ and $\mathrm{N}-\mathrm{C}-\mathrm{N}$ stretching. ${ }^{4}$ However, this band is common for thio- and seleno-compounds, is sensitive to deuteration, and is found in 
the spectra of all thioamides and substituted thioureas except $N, N$-dialkylthioamides and tetraalkylthioureas. The main contribution to this band must therefore come from $\mathrm{N}-\mathrm{H}$ vibrations.

The $G$ band. The $G$ band is the only band which shows a significantly different location for thio- and seleno-compounds. It is, therefore, associated with the $\nu(\mathrm{CS})$ or $\nu$ (CSe) vibration, and this is also substantiated by a shift of this band towards lower frequencies on $S$ - or $S e$-alkylation or formation of metal complexes, reactions which diminish the double-bond character of the CS or CSe bond. The $\mathrm{G}$ band of primary and secondary thioamides and thioureas is slightly sensitive to $N$-deuteration which indicates some coupling with $\mathrm{NH}$ vibrations, and coupling may also occur with other vibrations. ${ }^{6,7}$ On the whole, however, the $\mathrm{G}$ band is probably due to a fairly pure CS or CSe vibration. In the spectra of the thio compounds it is found in the range usually cited for the single-bond $C-S$ stretching vibration $\left(600-800 \mathrm{~cm}^{-1}\right)$ or in a few cases (thioformamides, dithioamides, tertiary thioamides) somewhat higher; for the seleno compounds it is found at 30 to $100 \mathrm{~cm}^{-1}$ lower frequencies.

Earlier assignments for the CS stretching frequency have ranged as high as $1413 \mathrm{~cm}^{-1}$ in thiourea, ${ }^{21} 1130-1330 \mathrm{~cm}^{-1}$ in substituted thioureas, ${ }^{22}$ near $1100 \mathrm{~cm}^{-1}$ in thiolactams, ${ }^{1} 1360 \mathrm{~cm}^{-1}$ in thiosemicarbazides, ${ }^{23} 1000 \mathrm{~cm}^{-1}$ in thiobenzanilide, ${ }^{2}$ and 1216 or $980 \mathrm{~cm}^{-1}$ in thioacetamide. ${ }^{5,24}$

It now seems fully substantiated that the CS band of thioamides and thioureas will normally be found below $800 \mathrm{~cm}^{-1}$.

\section{DISCUSSION OF THE INFRARED SPECTRA OF INDIVIDUAL THIOAMIDES}

Thioformamides. A detailed study of the infrared spectrum of thioformamide was first published by Davies and Jones. ${ }^{25}$ More recently, Suzuki ${ }^{6}$ supplemented this work with observations on $N, N$-dideuteriothioformamide and supported the assignments with theoretical calculations.

Both Davies and Jones and Suzuki agree in assigning the most intense band at $1433 \mathrm{~cm}^{-1}$ chiefly to the $\nu(\mathrm{CN})$ vibration, but according to the calculations by Suzuki this vibrational mode couples almost completely with the $\delta(\mathrm{CH})$ vibration. The $\mathrm{CN}$ character of this $\mathrm{B}$ band is demonstrated by a major shift to $1610 \mathrm{~cm}^{-1}$ in $S$-methylthioformamidium iodide. At the same time the $\mathrm{A}$ band, which must be due essentially to $\mathrm{NH}_{2}$ deformation as it is replaced by deuteration, shows an upward frequency shift from 1612 to 1680 $\mathrm{cm}^{-1}$, which also indicates that this band has some CN character. The B band is shifted slightly toward higher frequencies on deuteration.

The increase in frequency of the $C$ band from $1324 \mathrm{~cm}^{-1}$ to $1395 \mathrm{~cm}^{-1}$ on $S$-methylation is consistent with the findings of Suzuki, who attributes it to a mixed CN and CH vibration. Davies and Jones assigned this band to the $\delta(\mathrm{CH})$ vibration and a band at $1288 \mathrm{~cm}^{-1}$ to the NCS group, but these assignments should be reversed since the $1288 \mathrm{~cm}^{-1}$ band is only little influenced by $S$-methylation.

According to Suzuki a band at $1125 \mathrm{~cm}^{-1}$ should be due to an $\mathrm{NH}_{2}$ vibration with a small contribution from the CS vibration, but the band is unchanged on $S$-methylation. Instead, the $\mathrm{D}$ band is considered to be a band near 1000

Acta Chem. Scand. 20 (1966) No. 3 


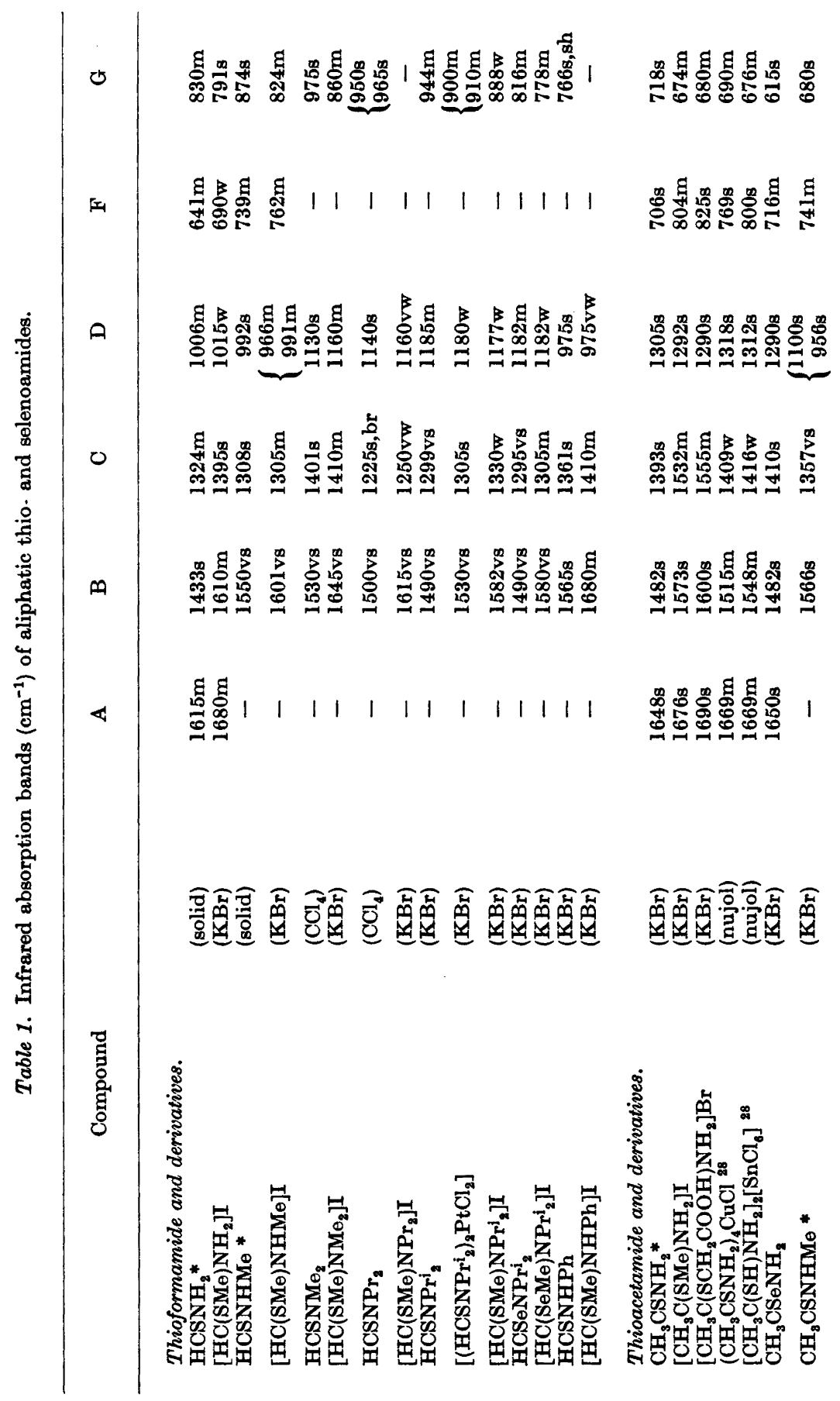

Acta Chem. Scand. 20 (1966) No. 3 


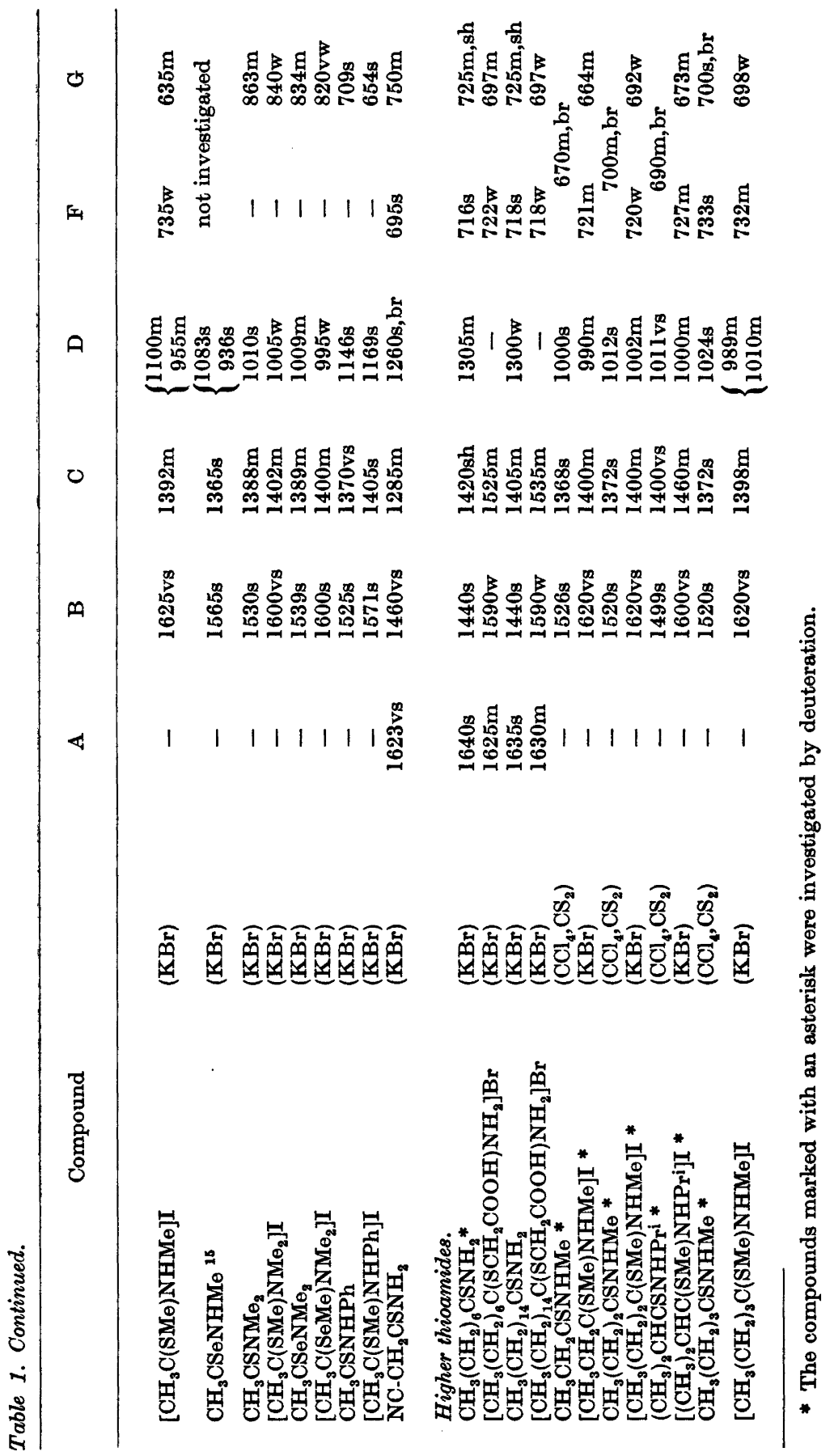

Acta Chem. Scand. 20 (1966) No. 3 
$\mathrm{cm}^{-1}$. It was assigned to a $\mathrm{CH}$ vibration by the above-mentioned authors, but it almost disappears on addition of methyl iodide to thioformamide, whilst the frequency remains essentially unchanged $\left(1013 \mathrm{~cm}^{-1}\right)$, so at least some skeletal vibrational influence must occur.

The band at $641 \mathrm{~cm}^{-1}$ is shifted on $S$-methylation to $690 \mathrm{~cm}^{-1}$ and disappears on deuteration; it can thus safely be identified with the $F$ band due to the $\mathrm{NH}_{2}$ group. The $\mathrm{G}$ band is found at $830 \mathrm{~cm}^{-1}$ and is shifted to $791 \mathrm{~cm}^{-1}$ on $S$-methylation. An investigation of selenoformamide would definitely decide whether this band arises from the CS vibration, but attempts to prepare this hitherto unknown compound were unsuccessful.

The infrared spectra of $N$-methyl- and $N, N$-dimethylthioformamide have, of course, no A bands, but they show strong B bands at $1550 \mathrm{~cm}^{-1}$ and 1530 $\mathrm{cm}^{-1}$, respectively. Both bands are shifted to higher frequencies on $S$-methylation, characterising them as due essentially to the $\mathrm{CN}$ grouping. However, according to Suzuki, this vibration in the monomethyl derivative couples with $\mathrm{NH}$ and $\mathrm{CH}_{3}$ vibrations.

Only very small changes occur in the $1100-1500 \mathrm{~cm}^{-1}$ range on $S$-methylation of $\mathrm{N}$-methylthioformamide; therefore the presence of the $\mathrm{C}$ band could not be shown in this way, but was assigned according to Suzuki. ${ }^{8}$ However, the $992 \mathrm{~cm}^{-1}$ band is notably weakened and must, therefore, be the D band. This is in agreement with Suzuki, who attributes this band to CN and CS vibrations. On $S$-methylation, the $\mathbf{F}$ band is easily recognized by a shift from $739 \mathrm{~cm}^{-1}$ to $762 \mathrm{~cm}^{-1}$, and the $\mathrm{G}$ band by a shift in the opposite direction from $874 \mathrm{~cm}^{-1}$ to $824 \mathrm{~cm}^{-1}$.

The $\mathrm{C}$ and $\mathrm{D}$ bands of $N, N$-dimethylthioformamide are apparent by the shifts of the bands at $1401 \mathrm{~cm}^{-1}$ and $1130 \mathrm{~cm}^{-1}$ to $1410 \mathrm{~cm}^{-1}$ and $1160 \mathrm{~cm}^{-1}$, respectively, on $S$-methylation. No $\mathrm{F}$ band is present, the $\mathrm{NH}_{2}$ group being fully substituted. The $G$ band is considered to be a strong band at $975 \mathrm{~cm}^{-1}$, shifted to $860 \mathrm{~cm}^{-1}$ on $S$-methylation. This is an unusual high frequency for a $\mathrm{G}$ band, but this assignment is confirmed by consideration of the spectra of other $N, N$-dialkylthioformamides and especially by comparison of $N, N$ diisopropylthioformamide with $N, N$-diisopropylselenoformamide, which we succeeded in preparing in analogous way as the sulfur compound. The spectra of these two compounds are as usual very similar, but the thioamide has a strong band at $944 \mathrm{~cm}^{-1}$ (shifted to lower frequencies on $S$-methylation or complex formation) which is missing in the spectrum of the selenium analogue; this has instead a medium strong band at $816 \mathrm{~cm}^{-1}$, shifted to $778 \mathrm{~cm}^{-1}$ on $S e$-methylation.

It may be of interest to compare the spectra of the thioformamides and the corresponding formamides. Actually, they are rather similar in the 1000$2000 \mathrm{~cm}^{-1}$ range if it is accepted that the $\mathrm{B}$ band is comparable to the amide I band. Then formamide ${ }^{26}$ has the amide II band at $1608 \mathrm{~cm}^{-1}$ comparable with the A band, the amide III band at $1309 \mathrm{~cm}^{-1}$ which is probably in this case quite comparable with our $\mathrm{C}$ band, and a band at $1090 \mathrm{~cm}^{-1}$ which probably corresponds to the $1125 \mathrm{~cm}^{-1}$ band of thioformamide. The strong $\delta(\mathrm{CH})$ vibration of formamide probably corresponds to the weak $1288 \mathrm{~cm}^{-1}$ band of thioformamide. The spectrum of $N, N$-dimethylformamide is also quite similar to that of $N, N$-dimethylthioformamide, except for the presence of the amide 
I band and the B band, respectively. The infrared spectrum of $N$-methylformamide $^{27}$ is more different from that of $N$-methylthioformamide, especially because the "amide II band of secondary amides" has no exact counterpart in the spectra of thioamides. It is found at almost the same place as the $\mathbf{B}$ band of the thio compound, but, as discussed above, they can hardly be considered analogous. $N$-Methylformamide and $N, N$-dimethylformamide have no counterparts of the $\mathrm{G}$ bands of $N$-methylthioformamide and $N, N$-dimethylthioformamide, thus confirming that the assignments of these bands to CS stretching is correct.

Thioacetamides. The use of the formation of salts and complex compounds in the identification of the bands in the infrared spectrum of thioacetamide has been demonstrated by Kutzelnigg and Mecke, ${ }^{28}$ who presented assignments for most of the frequencies observed. Later, Suzuki, ${ }^{7}$ supplemented this work with observations of deuterated thioacetamide and showed that the application of the Urey-Bradley force field successfully explained the main features of the spectrum.

Recently, Collard-Charon and Renson ${ }^{15}$ have investigated selenoacetamide in the range $900-1700 \mathrm{~cm}^{-1}$. They interpret their results to confirm the proposal set forth by Bellamy and Rogasch ${ }^{5}$ that the strong band found at 975 $\mathrm{cm}^{-1}$ in the spectrum of thioacetamide should be attributed chiefly to the CS group. However, the minor shift (to $955 \mathrm{~cm}^{-1}$ ) observed on going to selenoacetamide seems too small to warrant this conclusion. The band is weakened somewhat on $S$-protonation, $S$-methylation, or complex formation but only shifted slightly (either upwards or downwards) and is unchanged on deuteration. Accordingly, this band must essentially be due to a $\mathrm{CH}_{3}$ vibration $\left(\varrho\left(\mathrm{CH}_{3}\right)\right.$, according to Kutzelnigg and Mecke ${ }^{28}$ ) with some slight contribution from a CS vibration. This is in accordance with the calculations by Suzuki, ${ }^{7}$ who assigned the band to a combination of $\mathrm{CC}, \mathrm{CH}_{3}$, and $\mathrm{CS}$ vibrations.

We have investigated the infrared spectra of thioacetamide and selenoacetamide in the range $400-4000 \mathrm{~cm}^{-1}$. In our opinion, the spectra should be considered practically identical in the range $800-4000 \mathrm{~cm}^{-1}$, no bands being shifted more than $20 \mathrm{~cm}^{-1}$. However, two notable changes were observed below $800 \mathrm{~cm}^{-1}$. The strong doublet, $706+718 \mathrm{~cm}^{-1}$, is replaced by two other bands at $716 \mathrm{~cm}^{-1}$ and $615 \mathrm{~cm}^{-1}$ when going from thioacetamide to selenoacetamide. We feel that the $615 \mathrm{~cm}^{-1}$ band can, without doubt, be attributed to the CSe group; thus one of the bands in the doublet of thioacetamide must originate chiefly from the CS group. This is supported also by the calculation of Suzuki. ${ }^{7}$ Furthermore, the doublet at $460+472 \mathrm{~cm}^{-1}$ in the spectrum of thioacetamide has disappeared in the spectrum of selenoacetamide, which lends strong support to Suzuki's suggestion that this is due to a NCS deformation mode. Probably a new band found at $403 \mathrm{~cm}^{-1}$ in the spectrum of selenoacetamide should be attributed to a skeletal vibration of the same kind.

The A, B, C, D, and F bands are easily identified in the spectrum of thioacetamide. According to Suzuki the $1482 \mathrm{~cm}^{-1}$ band is chiefly associated with the $\delta_{\mathrm{a}}\left(\mathrm{CH}_{3}\right)$ vibration (although with some coupling with the $v(\mathrm{CN})$ vibration); however, the shifts to higher frequencies on $S$-methylation, $S$-protonation, or formation of complex compounds are considerable, showing unambiguously that this band is a B band. The $\mathrm{C}$ band is affected similarly and weakened 


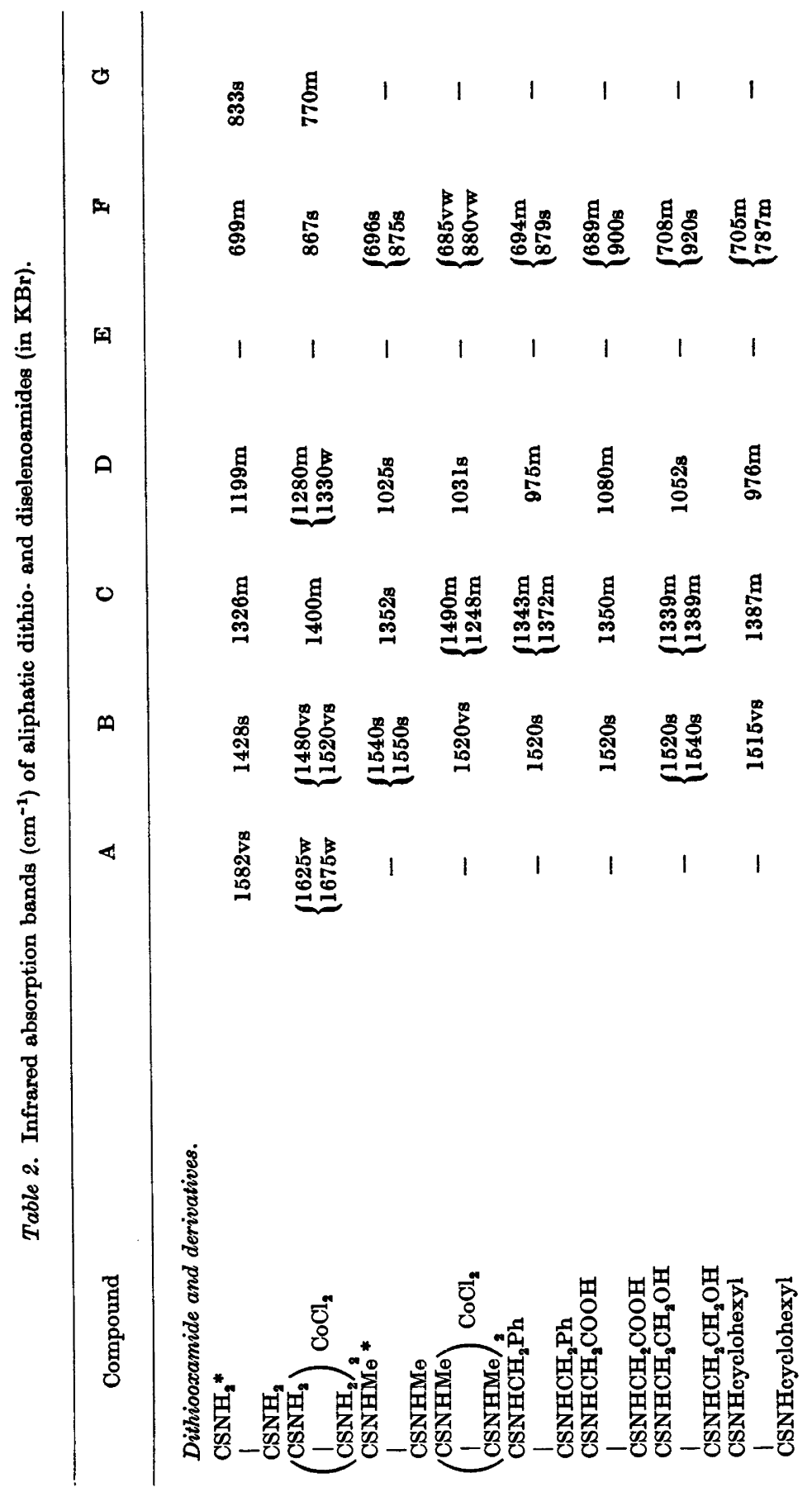

Acta Chem. Scand. 20 (166) No. 3 
THIOAMIDES AND SELENOAMIDES

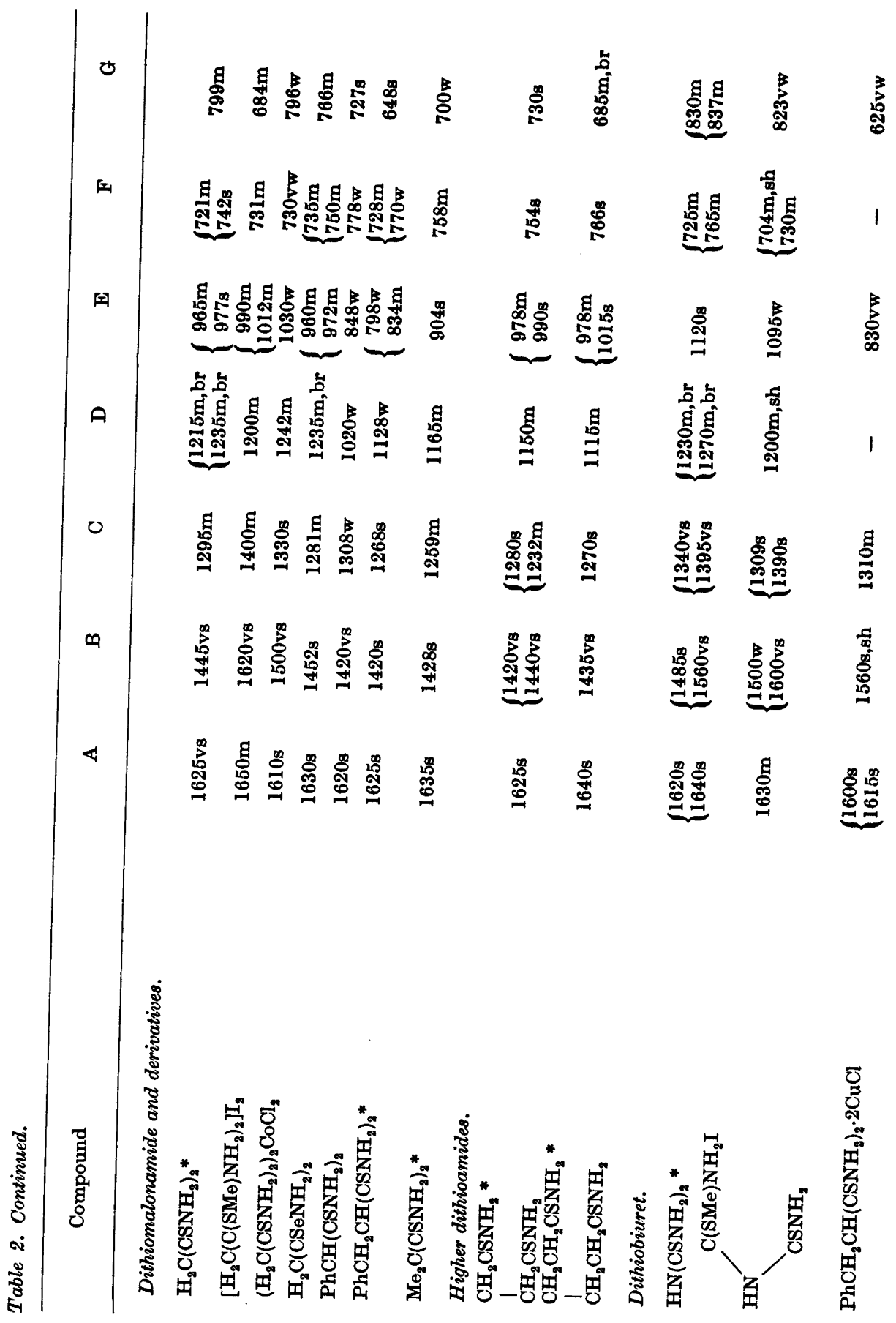

Acta Chem. Scand. 20 (1966) No. 3 
considerably; it cannot therefore, be due to a $\delta\left(\mathrm{CH}_{3}\right)$ vibration as supposed by Kutzelnigg and Mecke. ${ }^{28}$ The $\mathrm{D}$ band is only little influenced by $S$-methylation, and like the $\mathrm{A}, \mathrm{B}$, and $\mathrm{C}$ bands, is very little affected by selenation, but (in contrast to the $\mathrm{B}$ and $\mathrm{C}$ bands) very sensitive to deuteration. The $\mathrm{F}$ band is affected both by $S$-methylation and deuteration.

Collard-Charon and Renson ${ }^{15}$ have assigned bands near $1100 \mathrm{~cm}^{-1}$ in the spectra of $N$-methylthioacetamide and $N, N$-dimethylthioacetamide to the CS group but, for the reasons mentioned above, these assignments are considered incorrect. Rather, we assign the $\mathrm{G}$ band of $N$-methylthioacetamide to $680 \mathrm{~cm}^{-1}$, since this is shifted to a lower frequency on $S$-methylation. $N, N$-Dimethylthioacetamide has apparently two $G$ bands (863 and $655 \mathrm{~cm}^{-1}$ ) which are shifted to lower frequencies on selenation (to 834 and $606 \mathrm{~cm}^{-1}$, respectively) and $S$-methylation; however, the $655 \mathrm{~cm}^{-1}$ band is probably comparable with the doublet at $460+472 \mathrm{~cm}^{-1}$ in the spectrum of thioacetamide (see above). It seems to be a general rule that the bands due to $\mathrm{C}-\mathrm{S}$ stretching and $\mathrm{N}-\mathrm{C}-\mathrm{S}$ deformation are found at considerably higher frequencies for tertiary than for secondary and primary amides, and an $\mathrm{N}-\mathrm{C}-\mathrm{S}$ deformation band may thus be found at such a high frequency that it may be confused with a $G$ band. The $D$ bands are tentatively assigned to $1100 \mathrm{~cm}^{-1}$ and $1010 \mathrm{~cm}^{-1}$ in these compounds. However, the skeletal vibrational nature of the $D$ bands does not seem to be pronounced, as they are little affected by $S$-alkylation or selenation.

The spectra of higher primary thioamides - as examples, caprylic thioamide, palmitic thioamide and 2-phenylthioacetamide were investigated show essentially the same features as the spectrum of thioacetamide (Table 1). The spectrum of cyanothioacetamide is more like that of dithiomalonamide, having a strong and broad D band.

Higher $\mathrm{N}$-methylthioamides. Collard-Charon and Renson ${ }^{15}$ have examined a series of secondary and tertiary thioamides in the range $900-2000 \mathrm{~cm}^{-1}$ by selenation and deuteration. We have extended the range of investigation of some of these secondary amides to cover the region $400-900 \mathrm{~cm}^{-1}$ and, on the basis of deuteration and alkylation studies, we assign the CS-vibration to ca. $700 \mathrm{~cm}^{-1}$ in line with thioacetamide.

The spectra permitted an easy identification of the B, C, and D bands to about $1500 \mathrm{~cm}^{-1}, 1400 \mathrm{~cm}^{-1}$, and $1000 \mathrm{~cm}^{-1}$, respectively. The deuterated spectra revealed some admixture of $\mathrm{NH}$ absorption in the $\mathrm{B}$ and $\mathrm{C}$ bands and proved the $\mathrm{D}$ bands to be due chiefly to the NH group. However, the $\mathrm{F}$ and $G$ bands could not be located with certainty, as considerable coupling seems to occur in the $650-750 \mathrm{~cm}^{-1}$ region.

The secondary thioamides examined all showed very strong and broad bands between 650 and $750 \mathrm{~cm}^{-1}$, whether the spectra were recorded of the thioamides as pure liquids or in solution. When the compounds were deuterated, these absorptions showed a general decrease in intensity, and at the same time a new pattern of well-defined bands appeared. This showed resemblance to the spectra of the $S$-methylated thioamides, except for the CS band, which was shifted toward lower frequencies. In this way the assignments of the G bands in the table were made, and the $\mathrm{F}$ bands were identified with the bands showing the most pronounced change on deuteration. 


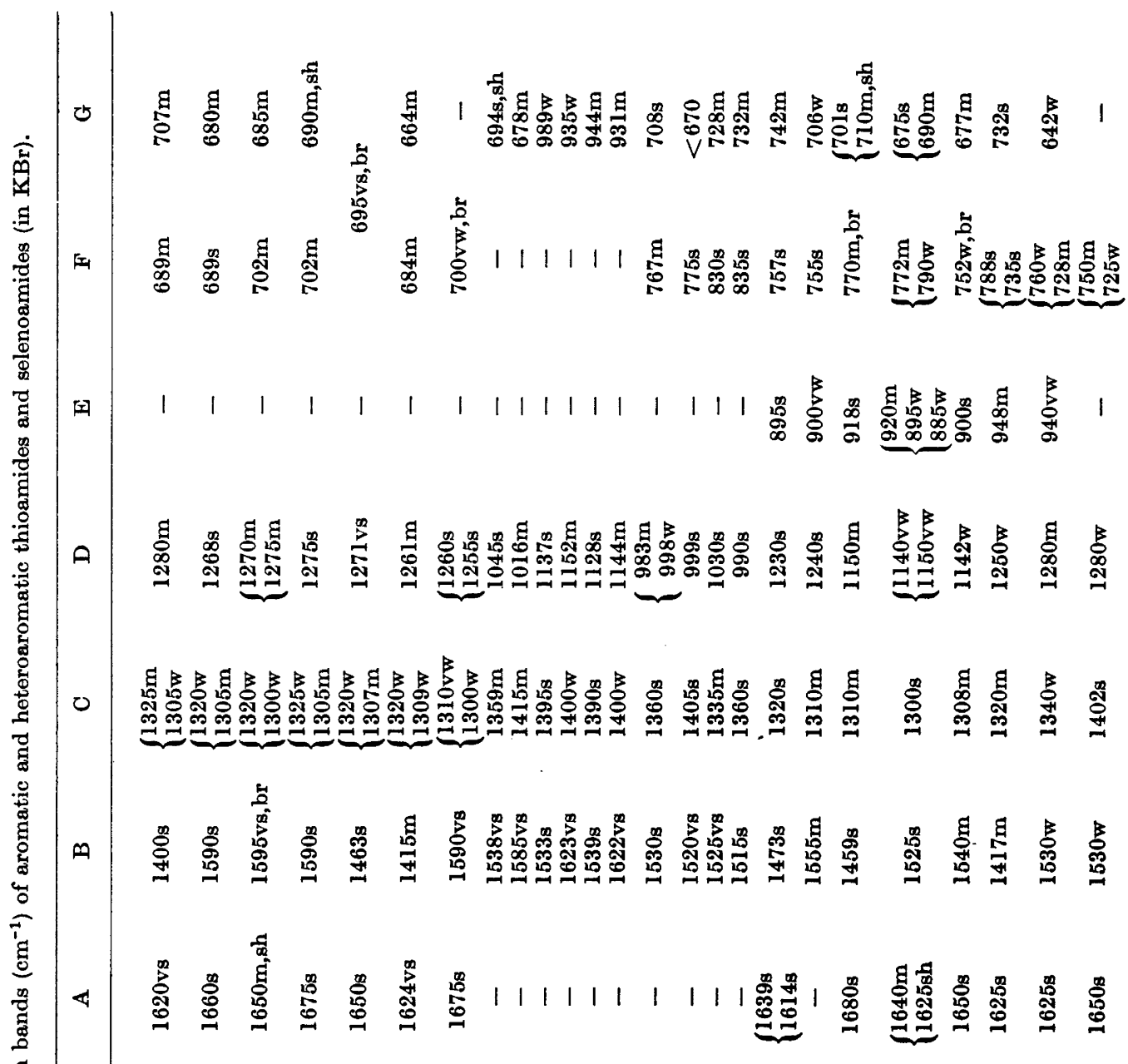


Dithioamides. The infrared spectrum of dithiooxamide (rubeanic acid) has been investigated by Scott and Wagner ${ }^{29}$ in the range $400-4000 \mathrm{~cm}^{-1}$. By comparison with oxamide and the deuterated species, assignments were made for the vibrational modes which were found consistent with the observed physical properties. The overall results show good agreement with the changes observed in the spectra on complex formation (Table 3) reported here. It is noteworthy that the $\mathrm{A}$ band at $1582 \mathrm{~cm}^{-1}$ due to the amino group shows a splitting when going from dithiooxamide to the cobalt(II) chloride complex or to the methyl iodide adduct. The reason for this might well be of a steric nature as no comparable effect is found for the higher thioamides, e.g. dithiomalonamide. Furthermore, the assignment of the strong band at $833 \mathrm{~cm}^{-1}$ to the CS group is chiefly supported by the shift to lower frequencies which reflects the diminished double-bond character induced by complex formation through the sulfur atom. The shoulder at $1326 \mathrm{~cm}^{-1}$ in dithiooxamide was not discussed by Scott and Wagner; however, the shifts observed on methylation $\left(1400 \mathrm{~cm}^{-1}\right)$ obviously characterises it as the $\mathrm{C}$ band.

While the $N, N^{\prime}$-disubstituted dithiooxamides all exhibit easily recognizable B, C, and D bands the $\mathbf{F}$ bands seem to be doubled. This may be inferred from the replacement of the band near $700 \mathrm{~cm}^{-1}$ as well as the band found in the $800-920 \mathrm{~cm}^{-1}$ range in the deuterated compounds. In $N, N^{\prime}$-dimethyldithiooxamide, a new band appeared at $731 \mathrm{~cm}^{-1}$ on deuteration which could be ascribed to the CS group in analogy with the corresponding band identified in deuterated dithiooxamide ${ }^{29}$ at $746 \mathrm{~cm}^{-1}$. However, these conclusions are useless for analytical purposes and we have thus omitted such assignments from the table.

We have prepared diselenomalonamide with a view to locating the position of the CS-vibration in dithiomalonamide. Only very small variations in intensity and position could be detected when these patterns were compared except for the shift of a weak to medium intensity band in dithiomalonamide at $799 \mathrm{~cm}^{-1}$ to $766 \mathrm{~cm}^{-1}$ in diselenomalonamide and the appearance of a new band at $1515 \mathrm{~cm}^{-1}$ in some samples of the latter compound. While the origin of the $1515 \mathrm{~cm}^{-1}$ band is obscure, we attribute the peak at $799 \mathrm{~cm}^{-1}$ in dithiomalonamide to the CS group. This correlation is further confirmed by the shift to lower frequencies (possibly $684 \mathrm{~cm}^{-1}$ ) found on the addition of methyl iodide and the minor change of position on deuteration. Attempts to oxidise diselenomalonamide to the corresponding cyclic diselenolyl salt, as reported for dithiomalonamide by Jensen, Baccaro and Buchardt, ${ }^{\mathbf{3 0}}$ were unsuccessful.

The pattern of the infrared spectrum of dithiobiuret is much like that of dithiomalonamide, except that much doublet splitting has occurred. As discussed earlier, ${ }^{30}$ this doubling disappears when dithiobiuret is oxidized to the dithiazolyl cation. The infrared spectrum shows weak bands which indicate that dithiobiuret partly exists in its tautomeric thiol form (SH band at 2600 $\mathrm{cm}^{-1}, \mathrm{C}=\mathrm{N}$ shoulder at $1660 \mathrm{~cm}^{-1}$ ), which may explain the presence of doublet absorption peaks. The NMR-spectrum is consistent with this proposal, as 3 single bands are found in DMSO in the intensity ratio $1: 2: 2,(\tau=-0.67$, +0.45 , and +0.83 , resp.). This definitely rules out the simple dithioamide structure, and suggests nearly complete conversion to the thiol form. Tautomerism is less likely in the case of dithiomalonamide: 
<smiles>NC(=S)NC(N)=S</smiles>

dithiobiuret<smiles>NC(=S)C[C@H](N)S</smiles>

dithiomalonamide

Aromatic thioamides. The attachment of an aromatic nucleus to the thioamide grouping appears to be of only minor influence on the position of the characteristic bands (Table 3). Irrespective of the great number of bands in the spectra arising from the benzene nucleus, a systematic study involving selenation, deuteration, complexing, and alkylation served to identify the 6 bands which are expected for the thioamide grouping in thiobenzamide. In the $1200-1700 \mathrm{~cm}^{-1}$ range a total of eight bands was found, of which the three bands at $1449 \mathrm{~cm}^{-1}, 1490 \mathrm{~cm}^{-1}$, and $1593 \mathrm{~cm}^{-1}$ could be attributed unambiguously to the phenyl group on the basis of the above-mentioned investigations. The remaining 5 bands are considered to be the $\mathrm{A}, \mathrm{B}, \mathrm{C}$, and $\mathrm{D}$ bands, the $\mathrm{C}$ band apparently showing a splitting. From the table it can be seen, that while the $A$ and $B$ bands behave normally, the $C$ and $D$ bands are, to a certain degree, unaffected by the classification tests. Deuteration proved both bands to possess some NH-character, but their origins are still in doubt.

The $F$ and $G$ bands were identified by a comparison of the deuterated and the selenated compounds.

Thiobenzamide has a strong band at $885 \mathrm{~cm}^{-1}$ which is unaffected by deuteration but shifted slightly on complex formation (872s) or $S$-alkylation with methyl iodide (862s), ethyl chloride $(870 \mathrm{~s})$ or bromoacetic acid $(860 \mathrm{~m}, 900 \mathrm{~m})$. Selenobenzamide has a corresponding band at $835 \mathrm{~cm}^{-1}(\mathrm{~s})$. However, the infrared spectra of $S$-carboxymethylthiobenzamidium bromide and $S e$-carboxymethylselenobenzamidium bromide are practically identical in the $800-900$ $\mathrm{cm}^{-1}$ range whereas they differ very much in the $600-700 \mathrm{~cm}^{-1}$ range; the assignment of the $G$ band of thiobenzamide to $707 \mathrm{~cm}^{-1}$ rather than to 885 $\mathrm{cm}^{-1}$ is therefore undoubtedly correct.

The shift of the $D$ band from $1280 \mathrm{~cm}^{-1}$ to $1045 \mathrm{~cm}^{-1}$ when going from thiobenzamide to the $N$-methyl derivative parallels the behaviour of thioacetamide. The doublet at $687 \mathrm{~cm}^{-1}$ and $694 \mathrm{~cm}^{-1}$ in $N$-methylthiobenzamide probably consists of the $G$ band together with the phenyl group absorption ordinarily found at this place in the spectrum. In support of this, the $G$ band is lowered to $678 \mathrm{~cm}^{-1}$ on methylation with methyl iodide, while the phenyl absorption is shifted to $705 \mathrm{~cm}^{-1}$. Deuteration leaves the range $670-800$ $\mathrm{cm}^{-1}$ unchanged, thus the $\mathrm{F}$ band must be placed below this range. The superposition of the spectra of $N, N$-dimethylthiobenzamide and the selenoanalogue proved the $G$ bands to be located at $989 \mathrm{~cm}^{-1}$ and $944 \mathrm{~cm}^{-1}$, respectively. The methylated compounds showed the expected shifts to $935 \mathrm{~cm}^{-1}$ and 931 $\mathrm{cm}^{-1}$, respectively, as well as an upwards shift $\left(10 \mathrm{~cm}^{-1}\right)$ of the peaks due to the benzene ring at $c a .700 \mathrm{~cm}^{-1}$ and $760 \mathrm{~cm}^{-1}$.

The identification of the B, C, and D bands in more complicated derivatives of thiobenzamide presented no difficulties; however, the $F$ and $G$ bands, believed to be located in the range $670-900 \mathrm{~cm}^{-1}$, were intimately mixed.

Acta Chem. Scand. 20 (1966) No. 3 
In thiobenzanilide, four bands could be seen in this range, at $689,708,752$, and $767 \mathrm{~cm}^{-1}$, of which the $689 \mathrm{~cm}^{-1}$ band undoubtedly arises from a phenyl group vibration. The remaining three bands are considered due to mixed vibrations of the phenyl groups, the CS group, and the NH group; thus the assignments in the table cannot be used rigorously.

The infrared spectra of thiobenzanilide and some similar secondary thioamides have also been investigated by Hadzi. ${ }^{2}$ However, we do not agree with this author that the "thioureide band" of these compounds is comparable with the amide II band of secondary amides. The band does not disappear on deuteration but is only shifted to a slightly lower frequency.

The infrared spectrum of 3-pyridinethiocarboxamide (thionicotinamide) is abnormal in so far as the A band is found at an unusually high frequency $\left(1680 \mathrm{~cm}^{-1}\right)$ which is lowered on formation of a copper(I) chloride complex. The reason for this behaviour is found in the presence of a pronounced SH band at $2570 \mathrm{~cm}^{-1}$ in the spectrum of thionicotinamide, indicating that this thioamide has the tautomeric thiol structure. On the complex formation, or addition of hydrochloric acid, the SH band disappears. The complex has the composition of a thiocarboxamidopyridinium dichlorocuprate $(\mathrm{I})$, $\mathrm{H}_{2} \mathrm{NCS}-\mathrm{C}_{5} \mathrm{H}_{5} \mathrm{NH}^{+} \mathrm{CuCl}_{2}^{-}$; the shifts of the bands on formation of the complex from the hydrochloride show, however, that the dichlorocuprate(I) ion is attached to the thioamide grouping so that the structure of the complex may be written:

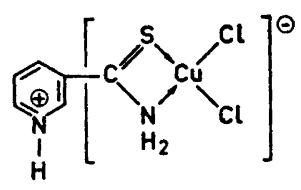

In 2-hydroxythiobenzamide, the splitting of the $\mathrm{A}$ band $\left(1614 \mathrm{~cm}^{-1}\right.$ and $1639 \mathrm{~cm}^{-1}$ ) as well as the presence of a broad band at $2600-2800 \mathrm{~cm}^{-1}$ indicates the occurrence of intramolecular hydrogen bonding. This compound further has an $\mathrm{E}$ band at $895 \mathrm{~cm}^{-1}$ and an $\mathrm{OH}$ deformation band at $1385 \mathrm{~cm}^{-1}$. On deuteration or formation of a nickel complex all these bands disappear. The absence of not only the $\mathrm{OH}$ band but also the $\mathrm{A}$ band in the spectrum of the nickel compound, as well as its analytical composition (ligand-metal ratio $1: 1)$ indicates that it is derived from the doubly charged phenolate-thioamidate anion of $o$-hydroxythiobenzamide. The $B$ band was identified by a shift from 1473 to $1555 \mathrm{~cm}^{-1}$ and the $G$ band by a shift from 742 to $706 \mathrm{~cm}^{-1}$ when the thioamide was transformed into the nickel compound.

Thiopiperidides. The thiopiperidides prepared in an earlier work ${ }^{31}$ all show very strong $B$ bands near $1500 \mathrm{~cm}^{-1}$ which move to $c a .1600 \mathrm{~cm}^{-1}$ on $S$-alkylation with methyl iodide or bromoacetic acid (Table 4). Some morpholides and piperazides studied by Goulden ${ }^{32}$ and Guépet et al $^{33}$ behave in the same way. On $S$-alkylation the CN bond attains considerable double-bond character without, however, reaching the normal $\mathrm{C}=\mathrm{N}$ vibration frequency. The lower values found can, of course, be attributed to resonance contribution from the sulfonium form to the predominating ammonium form of the cation. 
Table 4. Infrared absorption bands $\left(\mathrm{cm}^{-1}\right)$ of thiopiperidides and thiopiperididium salts.

\begin{tabular}{|c|c|c|c|c|c|}
\hline Compound & & $\mathbf{B}$ & $\mathbf{C}$ & $\mathrm{D}$ & $\mathbf{G}$ \\
\hline $\mathrm{HCSNC}_{5} \mathrm{H}_{10}$ & $\left(\mathrm{CCl}_{4}\right)$ & $1500 \mathrm{vs}$ & $1275 \mathrm{~m}$ & $\left\{\begin{array}{l}1135 \mathrm{~m} \\
1110 \mathrm{~m}\end{array}\right.$ & $912 \mathrm{~m}$ \\
\hline$\left.[\mathrm{HC}(\mathrm{SM})) \mathrm{NC}_{5} \mathrm{H}_{10}\right] \mathrm{I}$ & (KBr) & $1630 \mathrm{vs}$ & $1310 \mathrm{~m}$ & $\left\{\begin{array}{l}1140 \mathrm{w} \\
1090 \mathrm{~m}\end{array}\right.$ & $875 \mathrm{~m}$ \\
\hline $\begin{array}{l}\mathrm{CH}_{3} \mathrm{CSNC}_{5} \mathrm{H}_{10} \\
{\left[\mathrm{CH}_{3} \mathrm{C}(\mathrm{SMe}) \mathrm{NC}_{5} \mathrm{H}_{10}\right] \mathrm{I}} \\
{\left[\mathrm{CH}_{3} \mathrm{C}\left(\mathrm{SCH}_{2} \mathrm{COOH}\right) \mathrm{NC}_{5} \mathrm{H}_{10}\right] \mathrm{Br}}\end{array}$ & $\begin{array}{l}(\mathbf{K B r}) \\
(\mathbf{K B r}) \\
(\mathbf{K B r})\end{array}$ & $\begin{array}{l}1500 \mathrm{vs} \\
1597 \mathrm{vs} \\
1610 \mathrm{~s}\end{array}$ & $\begin{array}{l}1257 \mathrm{~s} \\
1275 \mathrm{w} \\
1275 \mathrm{w}\end{array}$ & $\begin{array}{c}1052 \mathrm{~s} \\
-\end{array}$ & $\begin{array}{c}657 \mathrm{~m} \\
643 \mathrm{~m} \\
-\end{array}$ \\
\hline$\left(\mathrm{CH}_{3}\right)_{3} \mathrm{C}-\mathrm{CSNC}_{5} \mathrm{H}_{10}$ & $(\mathrm{KBr})$ & $1423 \mathrm{vs}$ & $1249 \mathrm{~s}$ & $\left\{\begin{array}{l}1109 \mathrm{~m} \\
1131 \mathrm{~s}\end{array}\right.$ & $785 \mathrm{w}$ \\
\hline$\left[\left(\mathrm{CH}_{3}\right)_{3} \mathrm{C} \cdot \mathrm{C}(\mathrm{SMe}) \mathrm{NC}_{5} \mathrm{H}_{10}\right] \mathrm{I}$ & $(\mathbf{K B r})$ & $1550 \mathrm{vs}$ & $1239 \mathrm{~m}$ & $\left\{\begin{array}{l}1094 \mathrm{~m} \\
1134 \mathrm{w}\end{array}\right.$ & $777 \mathrm{w}$ \\
\hline $\mathrm{C}_{6} \mathrm{H}_{5} \mathrm{CSNC}_{5} \mathrm{H}_{10}$ & $(\mathbf{K B r})$ & $1492 \mathrm{~s}$ & $1200 \mathrm{~m}$ & $\left\{\begin{array}{l}1105 \mathrm{w} \\
1136 \mathrm{~m}\end{array}\right.$ & $677 \mathrm{w}$ \\
\hline$\left[\mathrm{C}_{6} \mathrm{H}_{5} \mathrm{C}(\mathrm{SMe}) \mathrm{NC}_{5} \mathrm{H}_{10}\right] \mathrm{I}$ & $(\mathbf{K B r})$ & $1587 \mathrm{vs}$ & $1195 \mathrm{w}$ & $\left\{\begin{array}{l}1092 \mathrm{w} \\
1135 \mathrm{vw}\end{array}\right.$ & $667 \mathrm{vw}$ \\
\hline $\begin{array}{l}p-\mathrm{MeO}-\mathrm{C}_{6} \mathrm{H}_{4} \mathrm{CSNC}_{5} \mathrm{H}_{10} \\
{\left[p-\mathrm{MeO}-\mathrm{C}_{6} \mathrm{H}_{4} \mathrm{C}\left(\mathrm{SCH}_{2} \mathrm{COOH}\right) \mathrm{NC}_{5} \mathrm{H}_{10}\right] \mathrm{Br}} \\
o-\mathrm{MeO}-\mathrm{C}_{6} \mathrm{H}_{4} \mathrm{CSNC} \mathrm{H}_{5} \mathrm{H}_{10} \\
m-\mathrm{ClC}_{6} \mathrm{H}_{4} \mathrm{CSNC}_{5} \mathrm{H}_{10} \\
{\left[o-\mathrm{Pr}^{\mathrm{i} O} \cdot \mathrm{C}_{6} \mathrm{H}_{4} \mathrm{C}\left(\mathrm{SCH}_{2} \mathrm{COOH}\right) \mathrm{NC}_{5} \mathrm{H}_{10}\right] \mathrm{Br}} \\
{\left[o-\mathrm{Bu}^{n} \mathrm{O} \cdot \mathrm{C}_{6} \mathrm{H}_{4} \mathrm{C}\left(\mathrm{SCH}_{2} \mathrm{COOH}\right) \mathrm{NC}_{5} \mathrm{H}_{10}\right] \mathrm{Br}} \\
\mathrm{C}_{6} \mathrm{H}_{5} \mathrm{CH}_{2} \mathrm{CH}_{2} \mathrm{CSNC}_{5} \mathrm{H}_{10}\end{array}$ & $\begin{array}{l}(\mathrm{KBr}) \\
(\mathrm{KBr}) \\
(\mathrm{KBr}) \\
(\mathrm{KBr}) \\
(\mathrm{KBr}) \\
(\mathrm{KBr}) \\
(\mathrm{KBr})\end{array}$ & $\begin{array}{l}1487 \mathrm{~s} \\
1604 \mathrm{~s} \\
1484 \mathrm{vs} \\
1493 \mathrm{vs} \\
1608 \mathrm{~s} \\
1603 \mathrm{~s} \\
1494 \mathrm{vs}\end{array}$ & & not identified & \\
\hline
\end{tabular}

According to Goulden, ${ }^{32}$ quaternization may lead to a decrease in the value of the $\mathrm{C}=\mathrm{N}$ frequency. However, the author came to this conclusion by comparing the quaternary ion, $\mathrm{C}_{6} \mathrm{H}_{5}-\mathrm{C}\left(\mathrm{SCH}_{3}\right)=\mathrm{N}^{+}\left(\mathrm{CH}_{3}\right) \mathrm{C}_{6} \mathrm{H}_{5}$, with the thioimidate $\mathrm{C}_{6} \mathrm{H}_{5}-\mathrm{C}\left(\mathrm{SCH}_{3}\right)=\mathrm{NC}_{6} \mathrm{H}_{5}$ rather than with the corresponding ternary cation $\mathrm{C}_{6} \mathrm{H}_{5}-\mathrm{C}\left(\mathrm{SCH}_{3}\right)=\mathrm{N}^{+} \mathrm{HC}_{6} \mathrm{H}_{5}$. The latter has the $\mathrm{B}$ band in almost the same place $\left(1555 \mathrm{~cm}^{-1}\right)$ as the quaternary ion $\left(1562 \mathrm{~cm}^{-1}\right)$. The $\mathrm{CN}$ bond in the thioimidate, on the other hand, is almost a normal double bond, because a sulfonium form with a negatively charged nitrogen atom can evidently make very little contribution to the structure. Therefore, the $\mathrm{C}=\mathrm{N}$ frequency is nearer to that of a normal $\mathrm{C}=\mathrm{N}$ bond; the frequency is lowered by the formation of a cation and not specifically by quaternization. An analogous lowering of the double-bond frequency (near $1700 \mathrm{~cm}^{-1}$ ) is not observed when imidic esters are transformed into their hydrochlorides, because there will be no significant contribution from the oxonium structure even in the cations.

The $\mathrm{C}$ and $\mathrm{D}$ bands in the spectra of thiopiperidides could, in most cases, be identified near 1250 and $1100 \mathrm{~cm}^{-1}$, respectively. They shift to higher frequencies on $S$-alkylation. The $G$ band, which is characterized by shifting to lower frequencies on $S$-alkylation, is located below $800 \mathrm{~cm}^{-1}$, except for thioformylpiperidine ( $c f$. the thioformamides).

Acta Chem. Scand. 20 (1966) No. 3 


\section{INFRARED SPECTRA OF THIOUREAS}

This class of compounds has not been studied very extensively,* with the exception of the first member, thiourea. Stewart's assignments for thiourea ${ }^{21}$ are largely incorrect and should be replaced by the more realistic approach of Yamaguchi et al., ${ }^{4,34}$ who have based their discussion on the concept of mixed vibrations. However, as already pointed out in the discussion of the characteristic bands, our experimental results do not in all cases support the assignments of Yamaguchi et al. ${ }^{4}$ The discrepancies are especially connected with the question of the degree of contribution of the CS stretching vibration to the various bands.

We have tried to solve some of these difficulties by a comparative study of the spectra of thioureas and selenoureas. Independently, Collard-Charon and Renson ${ }^{20}$ have made a similar comparative study of thioureas and selenoureas. However, these authors assign the band at $1086 \mathrm{~cm}^{-1}$ in the spectrum of thiourea to the CS group, whereas we suggest a considerable lower frequency $\left(629 \mathrm{~cm}^{-1}\right)$, primarily on the basis of the absence of the counterpart of this band in the spectrum of selenourea. This was not noted by Collard-Charon and Renson because of the limitation of the range investigated; consequently, this method is only safe in full-range investigations. The peak found at 629 $\mathrm{cm}^{-1}$ is shifted to $592 \mathrm{~cm}^{-1}$ in the spectrum of $S$-methylthiouronium iodide and to $c a .550 \mathrm{~cm}^{-1}$ in the spectra of complex compounds of thiourea, which also characterizes it as a $G$ band. The presence of a band due to the CSe group could not be ascertained for selenourea, as there is a broad band of medium intensity covering the $520-600 \mathrm{~cm}^{-1}$ range. However, the location of the $G$ band in the spectra of substituted selenoureas usually presented no difficulties.

It has been concluded that the lowering of the $727 \mathrm{~cm}^{-1}$ band of thiourea on formation of complex compounds with metal halides should be attributed to the reduced double bond character of the CS bond following complex formation and therefore does support the assignment of this band to the $\mathbf{C}=\mathrm{S}$ group. However, this band can, at most, share some CS character because deuteration causes a splitting of it into a weak band at $690 \mathrm{~cm}^{-1}$ and a medium intensity band at $670 \mathrm{~cm}^{-1}$, while methylation produces a small shift to $732 \mathrm{~cm}^{-1}$ in the opposite direction of that expected for a CS frequency. From the point of view adopted here, this band is obviously best characterized as the $F$ band. This is also supported by its absence in the spectra of tetrasubstituted thioureas. If this band is in part due to a torsional NH vibration, it is conceivable that the frequency should be lowered as a consequence of increased double bond character of the CN bond.

Swaminathan and Irving ${ }^{35}$ have recently criticized the results of Yamaguchi et al. ${ }^{4}$ on the infrared spectra of metal complexes of thiourea and claim that the differences between the infrared spectrum of thiourea itself and those of its metal complexes are confined to two bands only (our $\mathrm{C}$ and $\mathrm{G}$ band). However, our results with $\left[\mathrm{Pt}(\mathrm{tu})_{4}\right] \mathrm{Cl}_{2}$ have fully confirmed the results of Yamaguchi et al. that complex formation may increase the frequency of the

\footnotetext{
* However, infrared absorption bands have been reported for several substituted thioureas, $1,20,22,38,54,55$ especially in the $1500-1600 \mathrm{~cm}^{-1}$ range. ${ }^{54}$
}

Acta Chem. Scand. 20 (1966) No. 3 


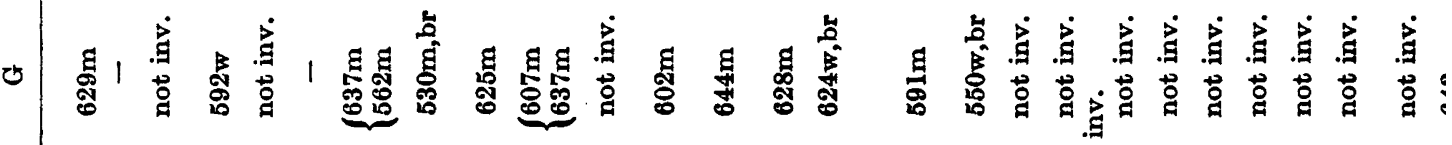

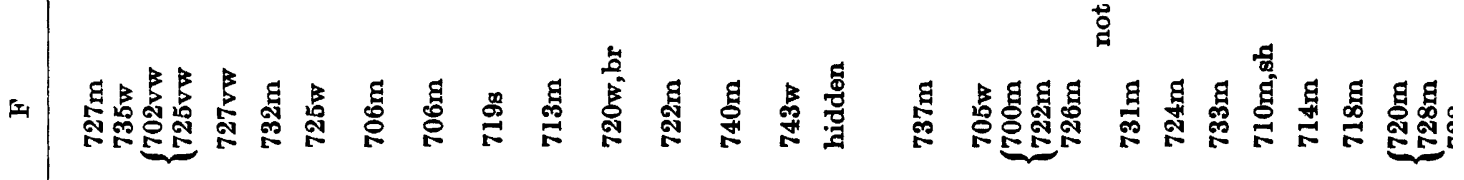

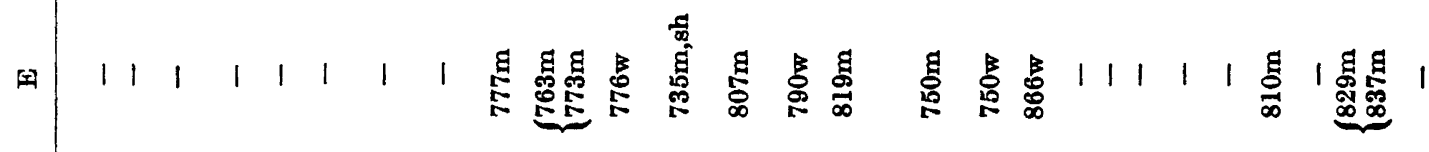

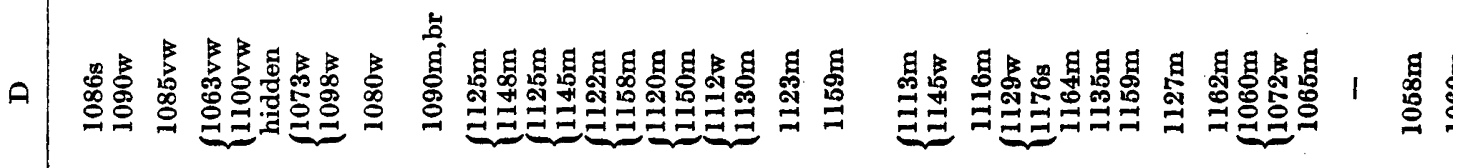

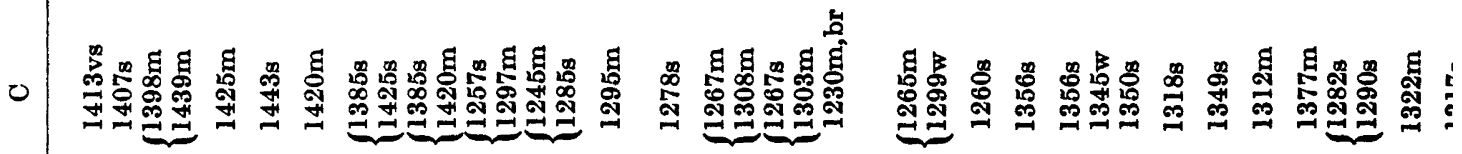

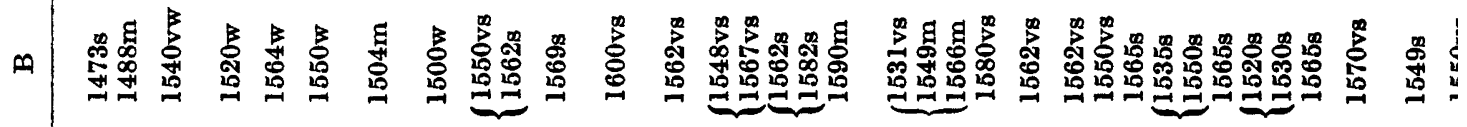

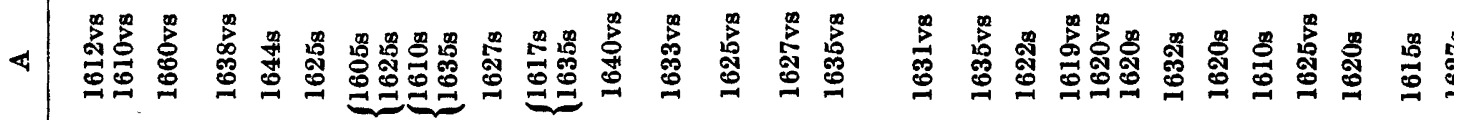

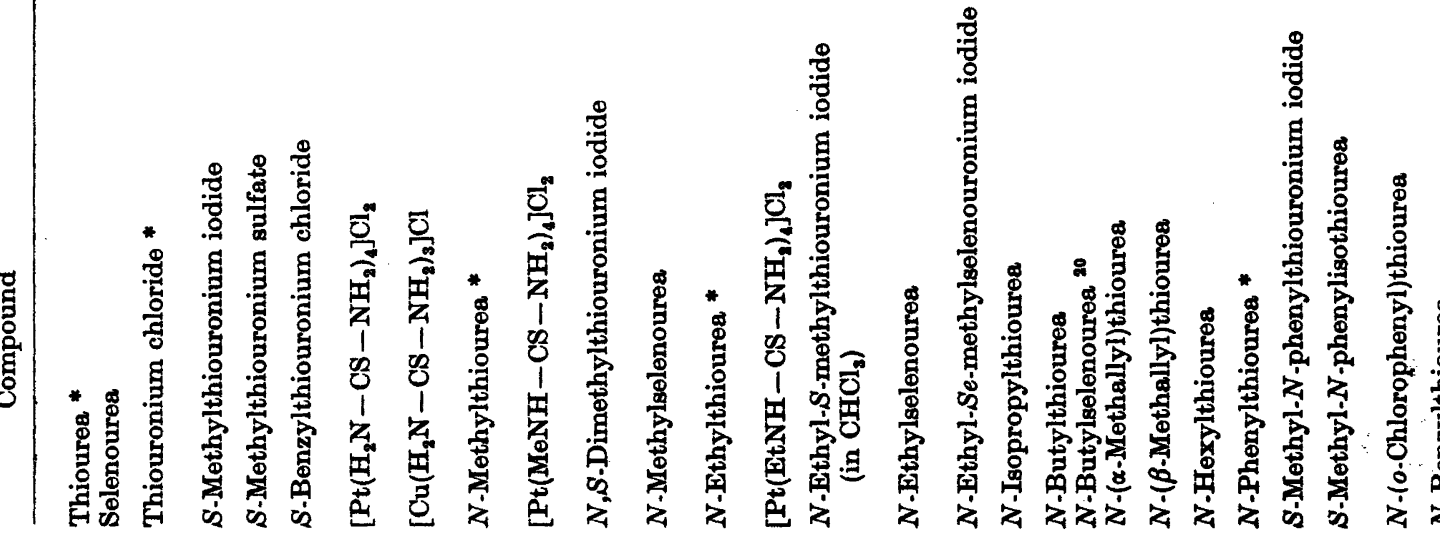

Acta Chem. Scand. 20 (1966) No. 3 
A, B, C, and also the $\mathrm{D}$ bands. This is also what would be expected for reactions which increase the double bond character of the CN bond (incidentally, the A band is not due to a pure $\mathrm{NH}_{2}$ vibration and the $\mathrm{C}$ band certainly not to $\mathrm{C}-\mathrm{S}$ stretching as maintained by Swaminathan and Irving). The increase in frequency of the $\mathrm{A}, \mathrm{B}, \mathrm{C}$, and $\mathrm{D}$ bands is very conspicuous on $S$-protonation and $S$-methylation, but is incontestable also in the spectra of many complexes, e.g. the nickel-thiourea complexes studied by Olliff, ${ }^{36}$ the $\mathrm{SnCl}_{4}$ and $\mathrm{SnBr}_{4}$ complexes of thiourea, ${ }^{37}$ and as a matter of fact, also in the spectra of the copper, cadmium, and mercury complexes published by Swaminathan and Irving. As would be expected, it is only weakly coordinated metal ions such as $\mathrm{Mn}^{2+}$, $\mathrm{Pb}^{2+}$, etc. which do not influence the $\mathrm{A}, \mathrm{B}$, and $\mathrm{D}$ bands perceptibly.

The changes of the spectrum of thiourea on $S$-protonation, $S$-methylation, and complex formation lend support to the view that the $\mathrm{B}, \mathrm{C}$, and $\mathrm{D}$ bands have their origin mainly in the $v_{\text {as }}(\mathrm{N}-\mathrm{C}-\mathrm{S}), v(\mathrm{~N}-\mathrm{C}-\mathrm{N})$, and $v_{\mathrm{s}}(\mathrm{N}-\mathrm{C}-\mathrm{S})$ vibrations, respectively. However, as shown below, considerable coupling with $\mathrm{NH}$ vibrations occur in substituted thioureas with secondary $\mathrm{NH}$ groups. The $\mathrm{F}$ and $\mathrm{G}$ bands are mainly due to $\mathrm{NH}$ and $\mathrm{CS}$ vibrations, respectively, as discussed above.

Monosubstituted thioureas. The strong, characteristic A and B bands were easily recognized in the infrared spectra of the monosubstituted thioureas investigated. Deuteration studies proved the $\mathbf{A}$ band to be essentially due to the amino group, while the B band, occasionally occurring as a strong doublet, was rather unaffected by this treatment, as in thiourea. The $\mathrm{C}$ band could, in all cases, be identified as the strongest band in the $1200-1400 \mathrm{~cm}^{-1}$ range. Being essentially a composite band, deuteration caused separation of the $\mathbf{N}-\mathbf{D}$ frequencies and the appearance of a strong band at, or just below, $1400 \mathrm{~cm}^{-1}$, parallelling the strong band in tetradeuterio-thiourea at $1380 \mathrm{~cm}^{-1}$. As the $\mathrm{C}$ band is not sensitive to $S$-alkylation, this component must, therefore, be due to the $\mathbf{N}-\mathrm{C}-\mathrm{N}$ grouping chiefly. The $\mathrm{D}$ band is the strongest band in the $1000-1200 \mathrm{~cm}^{-1}$ range, occurring at slightly higher frequencies in the aliphatic $\left(1125-1175 \mathrm{~cm}^{-1}\right)$ than in the aromatic $\left(c a .1060 \mathrm{~cm}^{-1}\right)$ thioureas, and assigned to the NH group (deuteration). The presence of an $\mathrm{E}$ band could only be ascertained in some of the lower thioureas, in the higher members of this series it must be very weak, if present. The $F$ band is only of analytical interest for the aliphatic thioureas, being obscured by the phenyl group absorptions in the aromatic compounds, in which its presence could only be detected through deuteration studies. The $\mathrm{G}$ band, in so far it has been sought for, was found in the range $625-650 \mathrm{~cm}^{-1}$ as for thiourea $\left(629 \mathrm{~cm}^{-1}\right)$. The criteria used for identification were the same as for thiourea.

Asymmetrically disubstituted thioureas. The general features of the few members investigated of this group (Table 6) are only to a small extent different from the monosubstituted thioureas. Thus the $\mathrm{C}$ bands are, contrary to the former group, unaffected by deuteration which indicates that the NH-character of the $\mathrm{C}$ bands in the monosubstituted thioureas originates from the secondary thioamide grouping. The $F$ band may be of analytical interest since it is located below $700 \mathrm{~cm}^{-1}$ in the $a s$-disubstituted, but in the range $700-750 \mathrm{~cm}^{-1}$ in the monosubstituted thioureas. This, together with the presence of the A band, helps to distinguish these compounds. 
THIOAMIDES AND SELENOAMIDES

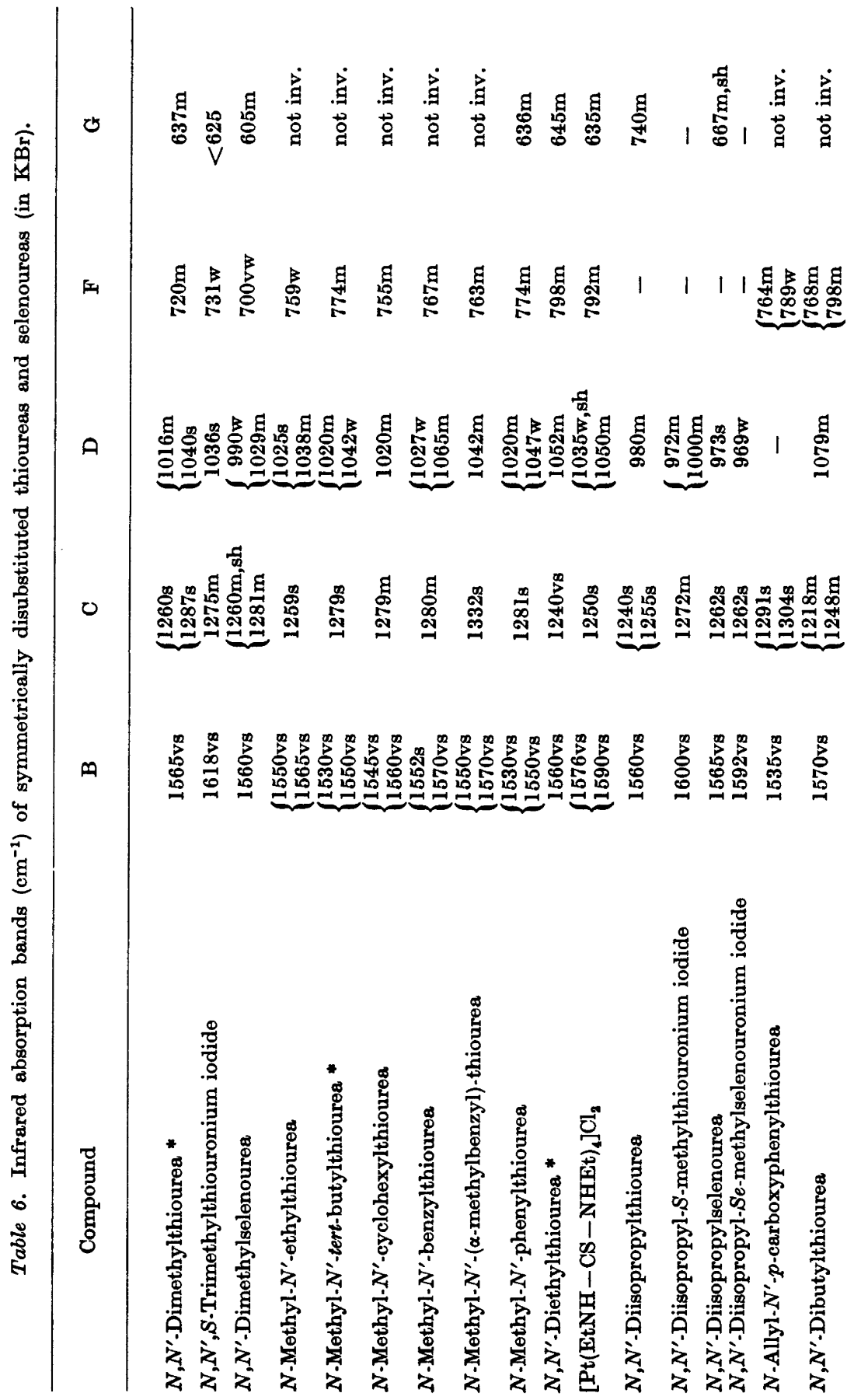

Acta Chem. Scand. 20 (1966) No. 3 


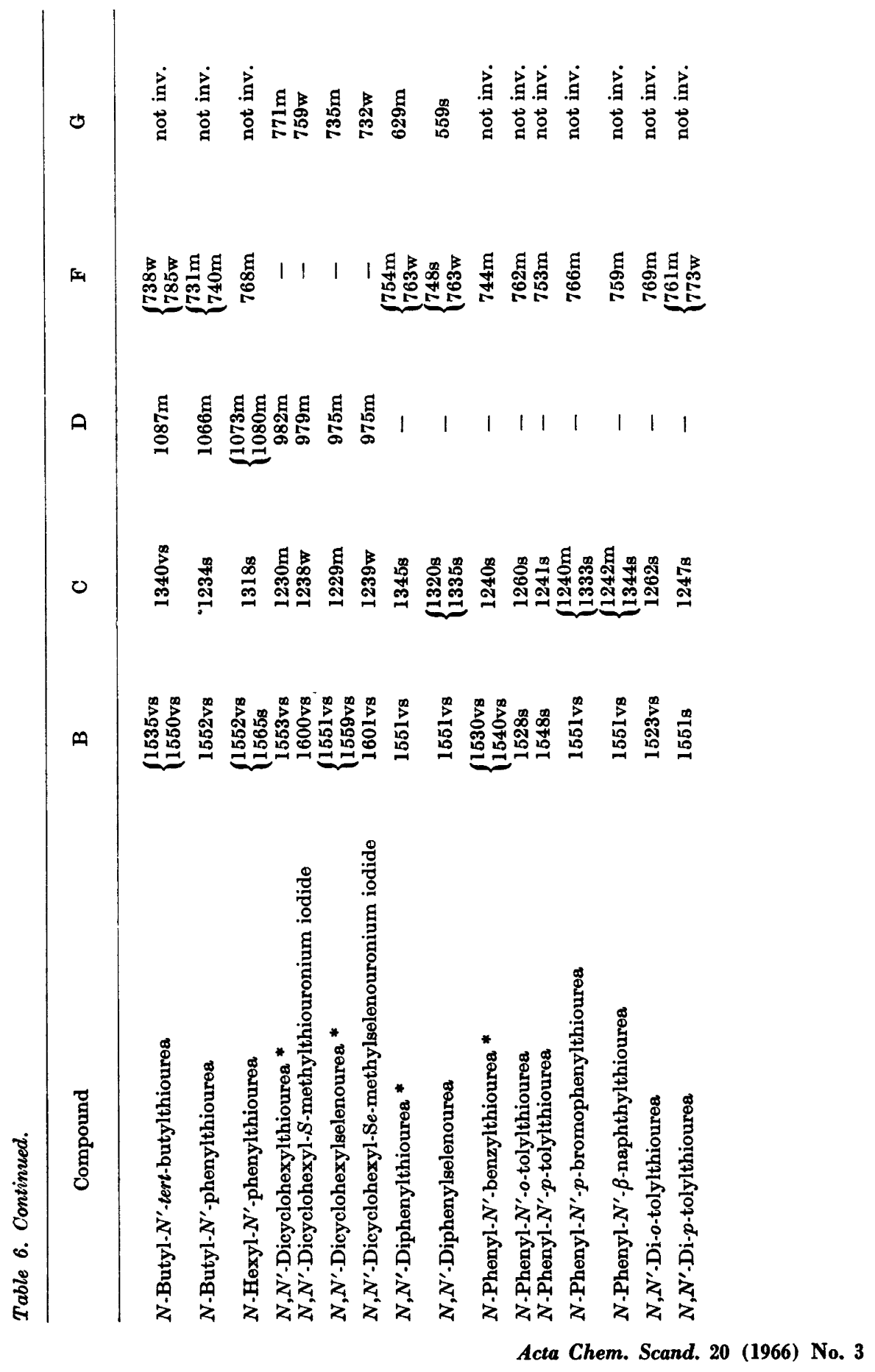


Symmetrically disubstituted thioureas. In these compounds the $\mathrm{A}$ and $\mathrm{E}$ bands are absent in accordance with the substitution at both nitrogen atoms. Furthermore, the $\mathrm{D}$ band is absent or very weak in symmetrically aromatic disubstituted thioureas, a feature also found in the asymmetrically disubstituted thioureas.

The location of the B, C, D, and F bands presented no difficulties for this group. However, in the aromatic compounds the $\mathrm{F}$ bands occur in the close vicinity of the phenyl group absorptions, and thus are dubious and of only little analytical interest. While the $B$ bands are unaffected by deuteration, the $\mathrm{C}$ bands were shifted to the $1350-1400 \mathrm{~cm}^{-1}$ region, thus considerable NH character seems to be present in these vibrations. It should be noted, that this is analogous to the behaviour of the monosubstituted thioureas, and therefore it appears that the NH-character in the $\mathrm{C}$ bands originates from a secondary amino group.

Trisubstituted thioureas. The location of the characteristic bands in the spectra of these compounds presented no difficulties. As expected, the $\mathrm{C}$ band proved to be composite, as deuteration caused the main peak to shift towards $1400 \mathrm{~cm}^{-1}$. From the results obtained, there seems to be a definite tendency for the $D$ band to be found in the range $1100-1150 \mathrm{~cm}^{-1}$ if the NH group is linked to an aromatic nucleus, but below $1100 \mathrm{~cm}^{-1}$ if the neighbouring group is aliphatic; however, further investigations are necessary to settle this proposal. It is interesting to find the $F$ band in trimethylthiourea at $900 \mathrm{~cm}^{-1}$, which is far beyond the range expected $\left(650-800 \mathrm{~cm}^{-1}\right)$; however, it is doubled on deuteration and no other absorptions could be detected in the region $670-900 \mathrm{~cm}^{-1}$. As a corresponding band is found for tetramethylthiourea, we assign this peak to a mixture of methyl and $\mathrm{NH}$ vibrations; this also accounts for the splitting observed in the spectrum of $S$-benzyl-trimethylthiouronium chloride $\left(866+898 \mathrm{~cm}^{-1}\right)$. In so far as the $G$ band was sought for it was found in the usual range.

Assignment of the $\mathrm{G}$ band by means of selenation was made for $N, N, N^{\prime}$ trimethylthiourea and $N, N$-dipropyl- $N^{\prime}$-cyclohexylthiourea. Although the infrared spectrum of the last-mentioned compound shows several bands in the $600-800 \mathrm{~cm}^{-1}$ range a comparison of its spectrum with that of the corresponding selenourea shows unambiguously that the $716 \mathrm{~cm}^{-1}$ band is the $G$, band because it is shifted to $623 \mathrm{~cm}^{-1}$ in the spectrum of the selenourea while three other bands $\left(746,685,643 \mathrm{~cm}^{-1}\right)$ remained almost unchanged in position and shape when going to the selenourea.

There was a corresponding shift of a band at $587 \mathrm{~cm}^{-1}$ to $525 \mathrm{~cm}^{-1}$ when going from this thiourea to the corresponding selenourea (and replacement of two bands at $595 \mathrm{~cm}^{-1}$ and $546 \mathrm{~cm}^{-1}$ by a band at $523 \mathrm{~cm}^{-1}$ in the case of trimethylthiourea); tentatively these bands are assigned to the $\mathrm{N}-\mathrm{C}-\mathrm{S}$ and $\mathrm{N}-\mathrm{C}-\mathrm{Se}$ deformation modes, $c f$. the bands found in the same range for thioacetamide.

Tetrasubstituted thioureas. The infrared spectra of tetrasubstituted thioureas are unusual in so far as they are almost identical in the $1000-4000 \mathrm{~cm}^{-1}$ range with the spectra not only of the corresponding selenoureas, but also of the corresponding ureas, except for the absence of the strong $\mathrm{C}=\mathrm{O}$ band, found near $1650 \mathrm{~cm}^{-1}$ in the spectra of tetrasubstituted ureas. This indicates

Acta Chem. Scand. 20 (1966) No. 3 
that the bands are mainly due to $\mathrm{C}-\mathrm{H}$ vibrations. Nevertheless, the $\mathrm{B}, \mathrm{C}$, and $\mathrm{D}$ bands could be located by $S$-methylation. The B band disappears (or is weakened considerably) on $S$-methylation and a new band appears at higher frequencies. A complex band near $1100 \mathrm{~cm}^{-1}$ is also affected significantly on $S$-methylation; some peaks are weakened and at least one is shifted toward higher frequencies; in Table 8 this band is considered (perhaps somewhat arbitrarily) to represent the $\mathrm{D}$ band. The $\mathrm{C}$ band is less characteristic, being only somewhat weakened on $S$-methylation. Below $1000 \mathrm{~cm}^{-1}$ the infrared spectra of corresponding tetrasubstituted thioureas and selenoureas are still very similar and quite different from the spectra of the corresponding ureas.

The $G$ band of tetrasubstituted thioureas is considered to be a band (usually rather weak) near $900 \mathrm{~cm}^{-1}$. This is a rather high frequency, in accordance with the values found for other tertiary thioamides. In the case of tetramethylthiourea the assignment is unambiguous. There are only very weak absorptions between $870 \mathrm{~cm}^{-1}$ and a medium strong band at $483 \mathrm{~cm}^{-1}(478 \mathrm{w}$ in the spectrum of tetramethylselenourea). A medium strong band at $870 \mathrm{~cm}^{-1}$ is shifted less than $5 \mathrm{~cm}^{-1}$ on $S$-methylation or selenation and is ascribed to the methyl groups; a corresponding band is found at $917 \mathrm{~cm}^{-1}$ in the spectrum of tetramethylurea. However, a weak, but sharp band at $956 \mathrm{~cm}^{-1}$ is split into three bands on $S$-methylation, is shifted to $920 \mathrm{~cm}^{-1}$ on selenation and is missing in the spectrum of tetramethylurea; it is therefore considered to be a G band.

Tetraethylthiourea has a medium strong band at $892 \mathrm{~cm}^{-1}$ which is affected by $S$-methylation, complex formation and selenation, and is missing in the spectrum of tetraethylurea. It is similarly considered to be a $\mathrm{G}$ band. However, the shifts of the $G$ bands on selenation are rather small for all tetrasubstituted thioureas, so that the $\mathrm{C}-\mathrm{S}$ vibrations seem to be coupled with $\mathrm{C}-\mathrm{H}$ vibrations.

\section{EXPERIMENTAL}

\section{In f r a red s pectra}

The infrared spectra were, in most instances, recorded on a Perkin-Elmer model 21 double beam spectrophotometer with $\mathrm{NaCl}$ optics or (for the range below $700 \mathrm{~cm}^{-1}$ ) with $\mathrm{KBr}$ optics. In addition, some of the spectra were recorded on a Perkin-Elmer model 125 grating spectrophotometer. Some of the thioureas were only recorded on a Perkin-Elmer "Infracord" spectrophotometer, and in these cases the range below $700 \mathrm{~cm}^{-1}$ was not investigated. In a few cases (indicated by references in the tables) data from the literature have been used. For all solid compounds the $\mathrm{KBr}$ disc technique was applied (300 mg of $\mathrm{KBr}$ mixed with ca. $1 \mathrm{mg}$ of the substance).

Deuteration could usually be performed by heating the compounds gently with heavy water until successive treatment only caused minor changes in the infrared spectra. In some instances it was found necessary to use dioxane or dimethylformamide as solvents, either because of low solubility or to minimize hydrolysis on heating the compound with heavy water.

\section{Com pounds}

Most of the compounds used for this investigation are well-known and were available from our stock of chemicals or were prepared by standard methods and recrystallised until pure, as shown by melting points or analyses. The following compounds are either new or require special comment:

Acta Chem. Scand. 20 (1966) No. 3 


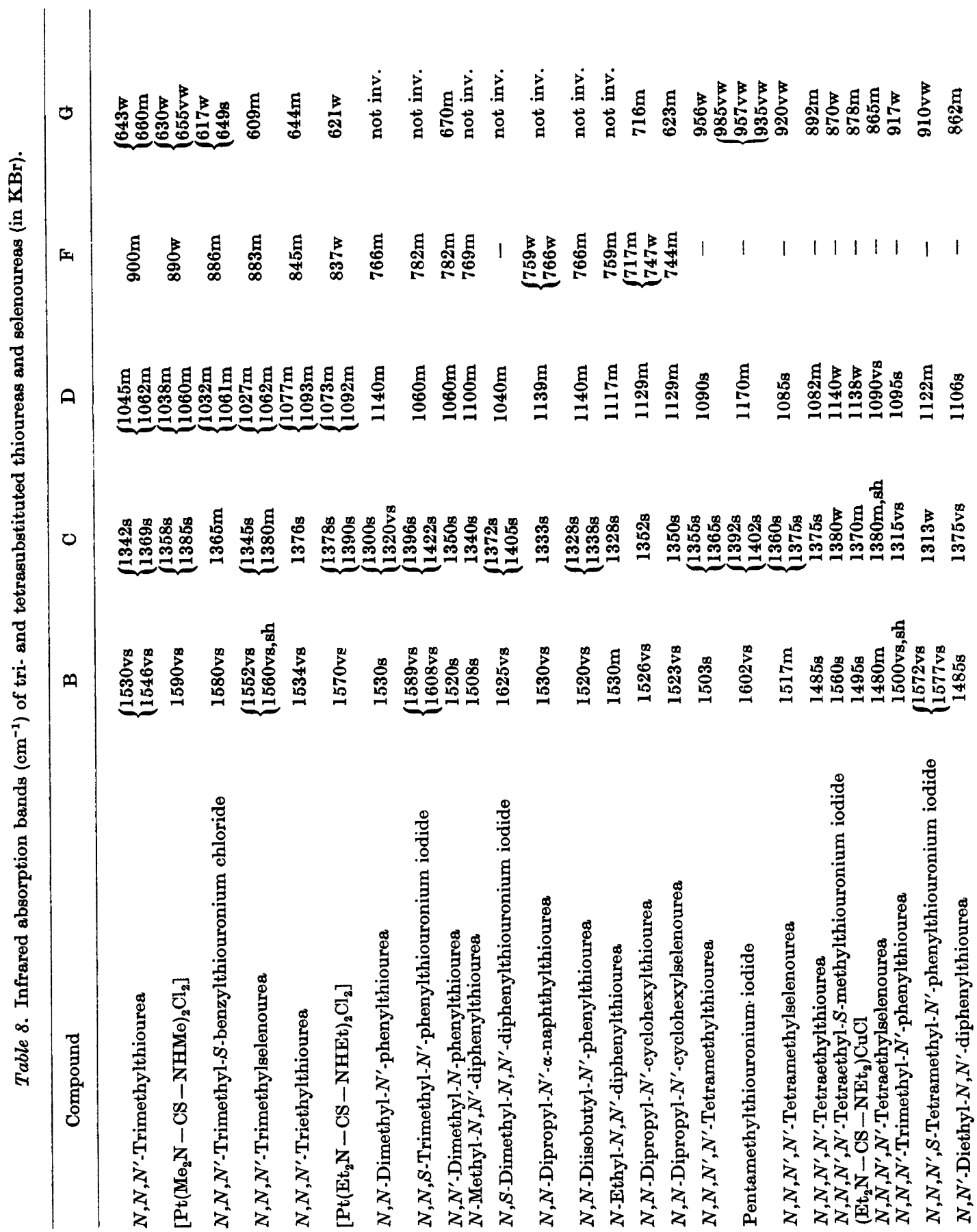

Acta Chem. Scand. 20 (1966) No. 3 


\section{Thioamides}

Most of the thioamides were prepared from the corresponding amides and phosphorus pentasulfide or from nitriles and hydrogen sulfide. The dialkylthioformamides were prepared by the recent method of Walter and Maerten. ${ }^{39}$ Some thioamides were prepared from dithioates and amines (cf. Holmberg ${ }^{40}$ ); this is a very convenient method when the carboxymethyl dithioate ${ }^{31}$ is in stock:

$\mathrm{N}$-Methylthioacetamide, $\mathrm{CH}_{3} \mathrm{CSNHCH}_{3}$. Carboxymethyl dithioacetate $(1.8 \mathrm{~g})$ was dissolved in $1 \mathrm{~N} \mathrm{NaOH}(10 \mathrm{ml})$ and $1 \mathrm{ml}$ of $40 \%$ aqueous methylamine solution was added. After $\frac{1}{2} \mathrm{~h}$ the solution was neutralised and extracted with ether. The ether was removed by evaporation. The residue was recrystallised from ether-light petroleum with addition of activated carbon. Yield: $0.40 \mathrm{~g}$, colourless crystals, m.p. $58^{\circ} \mathrm{C}$. (Found: C 40.30; $\mathrm{H}$ 7.91. Calc. for $\mathrm{C}_{3} \mathrm{H}_{7} \mathrm{NS}$ : $\mathrm{C} \mathrm{40.41;} \mathrm{H}$ 7.91). This compound has been prepared earlier from $N$-methylacetamide and phosphorus pentasulfide. ${ }^{41}$

In the same way were prepared: $N, N$-dimethylthioacetamide (m.p. $72-73^{\circ} \mathrm{C}$ ), $N$ methylthiobenzamide (m.p. $79-80^{\circ} \mathrm{C}$ ), $N, N$-dimethylthiobenzamide (m.p. $69-70^{\circ} \mathrm{C}$ ), $N$-methyl-p-butoxythiobenzamide (m.p. $60^{\circ} \mathrm{C}$ ), and $N$-isopropyl-p-butoxythiobenzamide $\left(\mathrm{m} . \mathrm{p} . \mathrm{73}^{\circ} \mathrm{C}\right)$. With the exception of the two last-mentioned these compounds had been prepared previously by other methods.

\section{Selenoamides}

Primary selenoamides were obtained from nitriles and hydrogen selenide, ${ }^{42} N$-substituted selenoamides (except diisopropylselenoformamide, see below) from the corresponding amides and phosphorus pentaselenide. ${ }^{15}$ The following compounds are new:

N,N-Diisopropylselenoformamide, HCSeNPri ${ }_{2}$. This compound was prepared by a modification of Walter and Maerten's method ${ }^{39}$ for the preparation of dialkylthioformamides. Negative results were obtained when the calculated amount or excess of hydrogen selenide was used, possibly because hydrogen selenide is a stronger acid than hydrogen sulfide.

Through an ice-cooled solution of sodium ethoxide (prepared from $23 \mathrm{~g}$ of sodium and $350 \mathrm{ml}$ of ethanol), which was swept free from oxygen by a stream of oxygen-free nitrogen, was passed a slow stream of hydrogen selenide until $64 \mathrm{~g}(0.8 \mathrm{~mole})$ had been absorbed. To the solution were added $20 \mathrm{~g}$ of diisopropylamine and $48 \mathrm{~g}$ of chloroform and the solution was refluxed for $48 \mathrm{~h}$ while allowing a slow stream of nitrogen to pass through the flask. After cooling, the solution was filtered and the precipitate ( $\mathrm{NaCl}$ and Se; $90 \mathrm{~g}$ ) was washed twice with ethanol. The combined solutions were evaporated in vacuo and the residue was extracted with chloroform. The filtered chloroform solution was washed with dilute hydrochloric acid and then water. After drying over $\mathrm{CaCl}_{2}$, the solvent was removed in vacuo to yield a red oil which partially crystallised on keeping for some days in a refrigerator. Recrystallisation from pentane yielded $5 \mathrm{~g}$ of orangeyellow crystals. The unsharp melting point and analyses of this product proved it to be impure and to contain excess selenium. It was, therefore, recrystallised with great loss from water and finally yielded $0.50 \mathrm{~g}(0.3 \%)$ of pale yellow crystals with $\mathrm{m} . \mathrm{p} .79-80^{\circ} \mathrm{C}$.

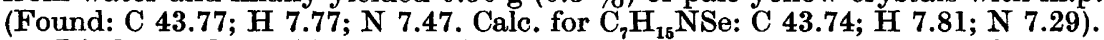

Diselenomalonamide, $\mathrm{CH}_{2}\left(\mathrm{CSeNH}_{2}\right)_{2}$. This compound was prepared from malononitrile and hydrogen selenide, using the directions for the preparation of dithiomalonamide (cf. Ref. 30). By recrystallisation of the brown, crude product $(8.4 \mathrm{~g}$ from $4 \mathrm{~g}$ of the nitrile) from methanol-water, made slightly acid with hydrochloric acid, diselenomalonamide was obtained as yellow crystals (yield $36 \%$ ) which, however, contained a trace of selenium. An analytically pure sample was obtained by precipitating it from a solution in dimethylformamide by addition of chloroform. M.p. $169-170^{\circ} \mathrm{C}$ (decomp.). (Found: $\mathrm{C} \mathrm{15.75;} \mathrm{H} 2.83 ; \mathrm{N} 12.38$. Calc. for $\mathrm{C}_{3} \mathrm{H}_{8} \mathrm{~N}_{2} \mathrm{Se}_{2}: \mathrm{C} 15.80 ; \mathrm{H} \mathrm{2.66;} \mathrm{N} 12.28$ ). At room temperature in absence of oxygen, the compound is fairly stable. However, it gradually loses hydrogen selenide and a nitrile band at $2200 \mathrm{~cm}^{-1}$ appears in the infrared spectrum, indicating transformation into cyanoselenoacetamide. The compound is sensitive to oxygen and oxidants but no diselenole derivative seems to be formed.

$\mathrm{N}, \mathrm{N}$-Dimethylselenobenzamide, $\mathrm{C}_{6} \mathrm{H}_{5} \mathrm{CSeN}\left(\mathrm{CH}_{3}\right)_{2}$. A solution of $60 \mathrm{~g}$ of $\mathrm{N}, \mathrm{N}$-dimethylbenzamide was added dropwise to a stirred suspension of $46 \mathrm{~g}$ of phosphorus pentaselenide

Acta Chem. Scand. 20 (1966) No. 3 
in $100 \mathrm{ml}$ of dry benzene. The mixture was refluxed for $36 \mathrm{~h}$, cooled, and filtered. Benzene and unreacted dimethylbenzamide were removed by distillation, first at normal pressure and finally at $0.1 \mathrm{~mm} \mathrm{Hg}$. The residue $(6 \mathrm{~g})$ was dissolved in benzene, and the solution was filtered. On addition of light petroleum and cooling, dimethylselenobenzamide separated as light yellow crystals $(4.0 \mathrm{~g}, 4.7 \%)$. Recrystallisation from benzene-light petroleum gave crystals, m.p. $79-80^{\circ} \mathrm{C}$. (Found: $\mathrm{C} 50.90 ; \mathrm{H} 5.30 ; \mathrm{N} 6.56$. Calc. for $\mathrm{C}_{9} \mathrm{H}_{11} \mathrm{NSe}$ C 50.95; H 5.24; N 6.60).

\section{Thioureas}

The following thioureas have not hitherto been described. They were obtained in almost quantitative yields from the appropriate amines (methylamine, butylamine, and dipropylamine) and isothiocyanates in ether and were recrystallised from ethanol-water or benzene-light petroleum.

N-Methyl-N'-cyclohexylthiourea, $\mathrm{C}_{8} \mathrm{H}_{16} \mathrm{~N}_{2} \mathrm{~S}$. M.p. $162-163^{\circ} \mathrm{C}$. Found: C 55.60; H 9.52; $\mathrm{N}$ 16.23. Calc.: C 55.76; $\mathrm{H} 9.38 ; \mathrm{N} 16.26$.

N-Butyl-N'-tert-butylthiourea, $\mathrm{C}_{9} \mathrm{H}_{20} \mathrm{~N}_{2} \mathrm{~S}$. M.p. $84-85^{\circ} \mathrm{C}$. Found: C 57.33; H 10.79; N 14.60. Calc.: C 57.38; H 10.72; N 14.88 .

$\mathrm{N}$-Methyl- $\mathrm{N}^{\prime}-\alpha$-methylbenzylthiourea, $\mathrm{C}_{10} \mathrm{H}_{14} \mathrm{~N}_{2} \mathrm{~S}$. M.p. $123-124^{\circ} \mathrm{C}$. Found: C 61.90 ; H 7.37; N 14.44. Calc.: C 61.81; H 7.28; N 14.42.

$\mathrm{N}, \mathrm{N}$-Dipropyl-N'-cyclohexylthiourea, $\mathrm{C}_{13} \mathrm{H}_{26} \mathrm{~N}_{2} \mathrm{~S}$. M.p. $68-69^{\circ} \mathrm{C}$. Found: C 64.33 ; H 11.02; N 11.60. Calc.: C 64.39; H 10.83; N 11.56 .

\section{Selenoureas}

The tetraalkylselenoureas have been described in a separate paper; ${ }^{56}$ the other selenoureas were prepared from cyanamides or carbodiimides and hydrogen selenide ${ }^{43}$ or from amines and isoselenocyanates. ${ }^{20,44}$ In addition to the tetraalkylselenoureas the following selenoureas are new:

N-Methylselenourea, $\mathrm{C}_{2} \mathrm{H}_{6} \mathrm{~N}_{2}$ Se. M.p. $154-155^{\circ} \mathrm{C}$. Prepared from methyl isoselenocyanate and ammonia in ether (yield $72 \%$ ) and recrystallised from benzene-light petroleum. (Found: C 17.53; H 4.47; N 20.00. Calc.: C 17.53; H 4.42; N 20.44).

$\mathrm{N}, \mathrm{N}^{\prime}$-Dimethylselenourea, $\mathrm{C}_{3} \mathrm{H}_{8} \mathrm{~N}_{2} \mathrm{Se}$. M.p. $110-111^{\circ} \mathrm{C}$. Prepared from methyl isoselenocyanate and methylamine in ether (yield $78 \%$ ) and recrystallised from benzenelight petroleum. (Found: $\mathrm{C} 24.23$; $\mathrm{H} \mathrm{5.24;} \mathrm{N}$ 18.30. Calc.: $\mathrm{C} 23.85 ; \mathrm{H} 5.35 ; \mathrm{N} 18.55$ ).

$\mathrm{N}, \mathrm{N}^{\prime}$-Diisopropylselenourea, $\mathrm{C}_{7} \mathrm{H}_{10} \mathrm{~N}_{2} \mathrm{Se}$. M.p. $167.5-168^{\circ} \mathrm{C}$. Prepared from $N, N^{\prime}-$ diisopropylcarbodiimide and hydrogen selenide (yield $70 \%$ ) and recrystallised from benzene. (Found: C 40.92; H 7.54. Calc.: C 40.58; H 7.78).

$\mathrm{N}, \mathrm{N}, \mathrm{N}^{\prime}$-Trimethylselenourea, $\mathrm{C}_{4} \mathrm{H}_{10} \mathrm{~N}_{2}$ Se. M.p. $105-106^{\circ} \mathrm{C}$. Prepared from methyl isoselenocyanate and dimethylamine in ethanol (yield $79 \%$ ) and recrystallised from benzene-light petroleum. (Found: C 29.34; H 6.20. Calc.: C 29.09; H 6.12).

N,N-Dipropyl-N'-cyclohexylselenourea, $\mathrm{C}_{13} \mathrm{H}_{20} \mathrm{~N}_{2}$ Se. M.p. 85-86 ${ }^{\circ} \mathrm{C}$. Prepared from dipropylamine and cyclohexyl isoselenocyanate in ethanol (yield $89 \%$ ) and recrystallised from ethanol-water. (Found: C 53.60; H 9.12; N 9.75. Calc.: C 53.96; H 9.08; $\mathrm{N} \mathrm{9.68).}$

\section{$S-A l k y l$ or Se-Alkyl derivatives}

The $S$-methyl or Se-methyl derivatives can often be obtained analytically pure and in almost quantitative yields by dissolving the thio- or seleno-compound in peroxidefree ether or (preferably) benzene, adding excess methyl iodide to the cooled solution and keeping it in a refrigerator for $1-3$ days. The crystalline compound, which separates, is isolated by centrifugation, washed with ether or benzene and dried in vacuo over phosphorus pentoxide. Recrystallisation is usually unnecessary and may yield inferior products. The compounds are very hygroscopic and are easily hydrolysed with the formation of methanethiol or methaneselenol. They are sensitive to oxygen and even in absence of air they often decompose rapidly. It has, therefore, not always been possible to determine a well-defined melting point.

The methyl iodide adducts of thioureas, except $N, N^{\prime}$-dicyclohexylthiourea, tetraethylthiourea, and $N, N, N^{\prime}$-trimethyl- $N^{\prime}$-phenylthiourea, and of the following thioamides 
were known: thioformamide, ${ }^{45}$ dimethylthioformamide, ${ }^{48}$ methylthioacetamide, ${ }^{41}$ dimethylthioacetamide, ${ }^{41}$ thioacetanilide, ${ }^{47}$ phenylthioacetamide, ${ }^{40}$ thiobenzamide, ${ }^{10} N$. methylthiobenzamide, ${ }^{50} \quad N, N$-dimethylthiobenzamide, ${ }^{50}$ thioformylpiperidine, ${ }^{46}$ thiopivaloylpiperidine, ${ }^{31}$ and thiobenzoylpiperidine ${ }^{s 1} S, N, N$-Trimethylthioacetamidium iodide and $S, N, N$-trimethylthiobenzamidium iodide were originally obtained by addition of methyl iodide to $S$-methyl $N$-methylthioimidates ${ }^{41,50}$ but were in this investigation prepared from the $N, N$-dimethylthioamides and methyl iodide. None of the methyl iodide adducts of selenoamides and selenoureas have hitherto been described.

The following preparations are typical:

S.Methylthioacetamidium iodide. Thioacetamide $(1.0 \mathrm{~g})$ and methyl iodide $(1.9 \mathrm{~g})$ were dissolved in peroxide-free ether $(20 \mathrm{ml})$ and the solution was kept for two days in a refrigerator. The crystals were isolated by centrifugation and washed with ether. Yield: $70 \%$; m.p. $132-133^{\circ} \mathrm{C}$. (Found: C 16.57; $\mathrm{H} \mathrm{3.75}$; $\mathrm{N}$ 6.48. Calc. for $\mathrm{C}_{3} \mathrm{H}_{8} \mathrm{NSI}_{\text {: }} \mathrm{C} 16.59$; $\mathrm{H} \mathrm{3.71;} \mathrm{N} \mathrm{6.45).}$

N,S-Dimethylthiobutyramidium iodide. The thioamide $(0.5 \mathrm{~g})$ was dissolved in $2 \mathrm{ml}$ of benzene and $2 \mathrm{~g}$ of methyl iodide were added. A yellow oil separated which crystallised on shaking and standing in a refrigerator. It was separated by centrifugation, washed with benzene, and dried in vacuo over phosphorus pentoxide. M.p. $112-113^{\circ} \mathrm{C}$. (Found: I 48.92. Calc. for $\mathrm{C}_{6} \mathrm{H}_{14} \mathrm{NSI}$ : I 48.97).

In a similar way, the following $S$-methyl derivatives were prepared (melting points are given in parentheses): Methiodides of $N$-methylthioformamide, $\mathrm{C}_{3} \mathrm{H}_{8} \mathrm{NSI}(\mathbf{9 1}-\mathbf{9 3})$, $N, N$-dimethylthioacetamide, $\mathrm{C}_{5} \mathrm{H}_{12} \mathrm{INS}(91-92$; this compound is mentioned in Ref. 41 but no m.p. was given), $N, N$-dipropylthioformamide, $\mathrm{C}_{8} \mathrm{H}_{18} \mathrm{INS}(98-100), N, N$-diisopropylthioformamide, $\mathrm{C}_{8} \mathrm{H}_{18} \mathrm{INS}(150-152)$, thioacetylpiperidine, $\mathrm{C}_{8} \mathrm{H}_{16} \mathrm{INS}(136-137)$, $N$-methylthiopropionamide, $\mathrm{C}_{5} \mathrm{H}_{12} \mathrm{INS}(127-129), \mathrm{N}$-isopropylthiobutyramide, $\mathrm{C}_{8} \mathrm{H}_{18} \mathrm{INS}$ $(100-102), N$-methylthiovaleramide, $\mathrm{C}_{7} \mathrm{H}_{18} \mathrm{INS}(113-115)$, thioformanilide, $\mathrm{C}_{8} \mathrm{H}_{10} \mathrm{INS}$ $(139-140), \quad N, N$-diisopropylselenoformamide, $\mathrm{C}_{8} \mathrm{H}_{18} \mathrm{INSe}(150-151), N, N$-dimethylselenoacetamide, $\mathrm{C}_{5} \mathrm{H}_{12} \mathrm{INSe}(102-104), N, N$-dimethylselenobenzamide, $\mathrm{C}_{10} \mathrm{H}_{14} \mathrm{INSe}$ (ca. 160, decomp.), $N, N$-dimethylselenourea, $\mathrm{C}_{4} \mathrm{H}_{11} \mathrm{IN}_{2} \mathrm{Se}(100-101), N$-ethylselenourea, $\mathrm{C}_{4} \mathrm{H}_{11} \mathrm{IN}_{2} \mathrm{Se} \quad(76-78), N, N$-diethylselenourea, $\mathrm{C}_{6} \mathrm{H}_{15} \mathrm{IN}_{2} \mathrm{Se} \quad(109-112), N, N^{\prime}$-diisopropylselenourea, $\mathrm{C}_{8} \mathrm{H}_{18} \mathrm{IN}_{2} \mathrm{Se}$ (ca. 130, decomp.), $N, N^{\prime}$-dicyclohexylthiourea, $\mathrm{C}_{14} \mathrm{H}_{27} \mathrm{IN}_{2} \mathrm{~S}$ $(139-142), N, N^{\prime}$-dicyclohexylselenourea, $\mathrm{C}_{14} \mathrm{H}_{27} \mathrm{IN}_{2} \mathrm{Se}(86-89)$, tetraethylthiourea, $\mathrm{C}_{10} \mathrm{H}_{23} \mathrm{IN}_{2} \mathrm{~S}(82-84), N, N, N^{\prime}$-trimethyl- $N^{\prime}$-phenylthiourea, $\mathrm{C}_{10} \mathrm{H}_{17} \mathrm{IN}_{2} \mathrm{~S}(113-114)$. Satisfactory analyses were obtained for all these new compounds.

In a few cases it was necessary to apply other solvents:

$\mathrm{S}, \mathrm{S}^{\prime}$-Dimethyldithiomalonamidium bis-iodide. Dithiomalonamide was dissolved in ethanol and excess methyl iodide was added. After $3 \mathrm{~h}$ the solution was filtered, benzene was added to initiate precipitation, and the solution kept for 4 days in a refrigerator. The white crystalline precipitate was filtered, washed with benzene, and dried in vacuo. M.p. $196-197^{\circ} \mathrm{C}$ (decomp.). (Found: I 62.25. Calc. for $\mathrm{C}_{5} \mathrm{H}_{12} \mathrm{I}_{2} \mathrm{~N}_{2} \mathrm{~S}_{2}: \mathrm{I}$ 60.68).

In a similar manner, but using methylcellosolve as a solvent, $S$-methyldithiobiuretium iodide was prepared from dithiobiuret; the mono-methiodide was formed even with large excess of methyl iodide. M.p. $132-134^{\circ} \mathrm{C}$. (Found: $\mathrm{I}$ 45.55. Calc. for $\mathrm{C}_{3} \mathrm{H}_{8} \mathrm{IN}_{3} \mathrm{~S}_{2}$ : I 45.76).

S-Carboxymethyl derivatives. The thioamides of caprylic and palmitic acid reacted very slowly with methyl iodide but reacted readily with bromoacetic acid in benzene solution at room temperature, giving $S$-carboxymethyl thiooctanamidium bromide, m.p. $134-135^{\circ} \mathrm{C}$. (Found: $\mathrm{Br} 26.53$. Calc. for $\mathrm{C}_{10} \mathrm{H}_{20} \mathrm{BrNO}_{2} \mathrm{~S}: \mathrm{Br} 26.81$ ) and $S$-carboxymethyl thiohexadecanamidium bromide, m.p. $137-138^{\circ} \mathrm{C}$. (Found: $\mathrm{Br} 19.70$. Calc. for $\mathrm{C}_{18} \mathrm{H}_{38} \mathrm{BrNO}_{2} \mathrm{~S}$ : $\mathrm{Br}$ 19.47). The other $S$-carboxymethyl derivatives have been described in earlier publications from this laboratory. ${ }^{30,31}$

The reaction product of selenobenzamide and methyl iodide was very unstable and could not be obtained in the pure state, but here again the reaction with bromoacetic acid proved advantageous. Selenobenzamide $(184 \mathrm{mg})$ was dissolved in hot benzene $(10 \mathrm{ml})$, the solution filtered, and mixed with a solution of bromoacetic acid (150 $\mathrm{mg})$ in benzene $(5 \mathrm{ml})$. There was an immediate separation of colourless crystals which were filtered after cooling of the solution in ice and washed with benzene. Yield: $224 \mathrm{mg}(71 \%)$ of $\mathrm{Se}-$ carboxymethyl selenobenzamidium bromide. This substance melts with decomposition at $c a .150^{\circ} \mathrm{C}$. 


\section{Metal complexes}

The platinum complexes were prepared according to Kurnakow ${ }^{52}$ who described the compounds of thiourea, $N$-methylthiourea, $N$-ethylthiourea, $N, N^{\prime}$-diethylthiourea, and $N, N, N^{\prime}$-triethylthiourea. Like the last of the aforementioned compounds, trimethylthiourea formed an orange-coloured, slightly soluble compound of the type $\mathrm{PtCl}_{2} \mathrm{~L}_{2}$. $N, N$-Diisopropylthioformamide formed an ochre complex of the same type.

The copper(I) chloride complexes were prepared by addition of a solution of copper(I) chloride in conc. hydrochloric acid to an aqueous or ethanolic solution of the thioamide, whereby the complex separated as a white (thiourea), yellow (phenylthioacetamide, benzyldithiomalonamide), red (thiobenzamide, thiobenzanilide), or red-brown (thionicotinamide) precipitate. With the exception of the already described thiourea complex ${ }^{53}$ they contained $\mathrm{CuCl}$ and the thioamide in the ratio $1: 1$, or, for the dithioamide, 2:1; the thionicotinamide complex contained in addition one mole of $\mathrm{HCl}$.

The cobalt(II) complexes were prepared by addition of an ethanolic solution of anhydrous cobalt(II) chloride to ethanolic solutions of the dithioamides. On cooling of the solutions dithiooxamide formed a red-brown and $N, N^{\prime}$-dimethyldithiooxamide a blackgreen precipitate; from the solution of the dithiomalonamide an olive-green complex was precipitated on addition of light petroleum. All these compounds contained $\mathrm{CoCl}_{2}$ and the dithioamide in the ratio $1: 1$.

Acknowledgements. The authors are indebted to the following who have assisted in the experimental work during its various stages: Hans P. Härter, Uffe Anthoni, Charles Larsen, Otto Dahl, Britta Mynster Dahl, Gideon Felbert, and Bruno Kägi.

We further wish to thank Dr. J. Feeney of Varian Associates Limited, Walton-onThames, for recording the NMR spectrum of dithiobiuret.

\section{REFERENCES}

1. Mecke, R., Jr. and Mecke, R. Chem. Ber. 89 (1956) 343.

2. Hadzi, D. J. Chem. Soc. 1957847.

3. Elmore, D. T. J. Chem. Soc. 19583489.

4. Yamaguchi, A., Penland, R. B., Mizushima, S., Lane, T. J., Curran, C. and Quagliano, J. V. J. Am. Chem. Soc. 80 (1958) 527.

5. Bellamy, L. J. and Rogasch, P. E. J. Chem. Soc. 19602218.

6. Suzuki, I. Bull. Chem. Soc. Japan 35 (1962) 1286.

7. Suzuki, I. Bull. Chem. Soc. Japan 35 (1962) 1449.

8. Suzuki, I. Bull. Chem. Soc. Japan 35 (1962) 1456.

9. Rao, C. N. R. and Venkataraghavan, R. Spectrochim. Acta 18 (1962) 541.

10. Rao, C. N. R., Venkataraghavan, R. and Kasturi, T. R. Can. J. Chem. 42 (1964) 36.

11. Jensen, K. A. Acta Chem. Scand. 17 (1963) 551.

12. Bellamy, L. J. The Infra-Red Spectra of Complex Molecules, 2nd Ed., Methuen \& Co., London 1958.

13. Janssen, M. J. Spectrochim. Acta 17 (1961) 475.

14. Hurd, R. N., DeLaMater, G., McElheny, G. C. and McDermott, J. P. Advances in the Chemistry of Coordination Compounds, p. 350. Proceedings of the Sixth International Conference on Coordination Chemistry. Edited by Stanley Kirschner, The Macmillan Co., New York 1961.

15. Collard-Charon, C. and Renson, M. Bull. Soc. Chim. Belges 72 (1963) 304.

16. Randall, H. M., Fowler, R. G., Fuson, N. and Dangl, R. Infrared Determination of Organic Structures, Van Nostrand, New York 1949.

17. Chatt, J., Duncanson, L. A. and Venanzi, L. M. Suomen Kemistilehti B 29 (1965) 75.

18. Miyazawa, T., Shimanouchi, T. and Mizushima, S. J. Chem. Phys. 24 (1965) 408.

19. Gerrard, W., Lappert, M. F., Pyszora, H. and Wallis, J. W. J. Chem. Soc. 19602144.

20. Collard-Charon, C. and Renson, M. Bull. Soc. Chim. Belges 72 (1963) 149.

21. Stewart, J. E. J. Chem. Phys. 26 (1957) 248.

22. Mecke, R., Jr., Mecke, R. and Lüttringhaus, A. Z. Naturforsch. 105 B (1955) 367.

23. Lieber, E., Rao, C. N. R., Pillai, C. N., Ramachandran, J. and Hites, R. D. Can. J. Chem. 36 (1958) 801. 
24. Mecke, R. and Spiesecke, H. Chem. Ber. 89 (1956) 1110.

25. Davies, M. and Jones, W. J. J. Chem. Soc. 1958955.

26. Suzuki, I. Bull. Chem. Soc. Japan 33 (1960) 1359.

27. Suzuki, I. Bull. Chem. Soc. Japan 35 (1962) 540.

28. Kutzelnigg, W. and Mecke, R. Spectrochim. Acta 17 (1961) 530.

29. Scott, T. A. and Wagner, E. L. J. Chem. Phys. 30 (1959) 465.

30. Jensen, K. A., Baccaro, H. R. and Buchardt, O. Acta Chem. Scand. 17 (1963) 163.

31. Jensen, K. A. and Pedersen, C. Acta Chem. Scand. 15 (1961) 1087.

32. Goulden, J. D. S. J. Chem. Soc. 1953997.

33. Guépet, R., Piganiol, P., Carayon-Gentil, A. and Chabrier, P. Bull. Soc. Chim. France 1965224.

34. Yamaguchi, A., Miyazawa, T., Shimanouchi, T. and Mizushima, S. Spectrochim. Acta 10 (1958) 170.

35. Swaminathan, K. and Irving, H. M. N. H. J. Inorg. Nucl. Chem. 26 (1964) 1291.

36. Olliff, R. W. J. Chem. Soc. 19652036.

37. Bystrov, D.S., Sumarokova, T. N. and Filimonov, V.N. Opt. Spectry. USSR 9 (1960) 239.

38. Ettlinger, M. G. J. Am. Chem. Soc. 72 (1950) 4699.

39. Walter, W. and Maerten, G. Ann. 669 (1963) 66.

40. Holmberg, B. Arkiv Kemi, Mineral. Geol. 24 A (1947) No. 3.

41. Knunyants, I. L. and Razvadovskaya, L. V. Zh. Obshch. Khim. 9 (1939) 557.

42. Brooker, L. G. S., Keyes, G. H. and White, F. L. J. Am. Chem. Soc. 57 (1935) 2494; Becker, W. and Meyer, J. Ber. 37 (1904) 2550.

43. Schmidt, H. Ber. 54 (1921) 2067; Zetzche, F. and Pinske, H. Ber. 74 (1941) 1022; Zingaro, R. A., Bennett, F. C. and Hammar, G. W. J. Org. Chem. 18 (1953) 292.

44. Pedersen, C. Th. Acta Chem. Scand. 17 (1963) 1457.

45. Bredereck, H., Gompper, R. and Seiz, H. Chem. Ber. 90 (1957) 1837.

46. Willstätter, R. and Wirth, T. Ber. 42 (1909) 1908, pp. 1920, 1921.

47. Diels, O. and Lichte, R. Ber. 59 (1926) 2778, p. 2784.

48. Bernthsen, A. Ann. 192 (1878) 1, p. 56.

49. Reynaud, P., Moreau, R. C. and Nguyen Hong Compt. Rend. 253 (1961) 1968.

50. Böttcher, B. and Bauer, F. Ann. 568 (1950) 218.

51. Peak, D. A. and Stansfield, F. J. Chem. Soc. 19524067.

52. Kurnakow, N. J. prakt. Chem. [2] 50 (1894) 480, 499, 500.

53. Walter, G. Ber. 64 (1931) 1087.

54. Kjær, A., Zahradnik, R., Dư̌k, K. and Klaban, K. Acta Chem. Scand. 16 (1962) 2041.

55. Chibisov, A. K. and Pentin, Yu. A. Zh. Obshch. Khim. 31 (1961) 11.

56. Jensen, K. A., Felbert, G. and Kägi, B. Acta Chem. Scand. 20 (1966) 281.

Received October 28, 1965. 